\title{
LOS FUNDAMENTOS DE LA DIVERSIDAD DEL SUR ANTE LA INTERVENCIÓN MILITAR
}

\author{
ÉLODIE BRUN \\ Marie-Françoise Valette
}

La Carta de San Francisco confirma el principio de la soberanía estatal (art. 2 §1), y su corolario, la no injerencia en los asuntos internos de los Estados miembros. El artículo $2 \$ 4$ prohíbe el uso de la fuerza armada; sin embargo, el capítulo viI presenta dos excepciones. ${ }^{1} \mathrm{Al}$ adherirse a las Naciones Unidas, los países del Sur aceptaron esas reglas. Ahora bien, desde los años noventa, el Consejo de Seguridad liberado de las restricciones de la Guerra Fría ha recurrido cada vez con más frecuencia a ese capítulo ${ }^{2}$ y no ha dudado en definir problemas internos de algunos Estados como amenazas contra la paz y seguridad internacionales.

El estudio de las posturas del Sur frente a esta evolución desemboca en una oposición entre las tesis soberanista y relativista. Según la primera, esos actores serían en su mayoría hostiles a la intervención militar por apego a la integridad de la soberanía. ${ }^{3} \mathrm{La}$ segunda defiende que no hay una posición a priori de los países en

${ }^{1}$ Por una parte, las operaciones de seguridad colectiva que se deciden en el Consejo de Seguridad (art. 42), y por otra, la legítima defensa (art. 51).

2 Antes de 1990, entre 5 y $10 \%$ de las resoluciones invocan el capítulo viI, para pasar a 25\% entre 1990 y 2002 y alcanzar el 47\% ese año. Peter Wallensteen y Patrik Johansson, "Security Council Decisions in Perspective", en David M. Malone (comp.), The UN Security Council, Boulder, Lynne Rienner Publishers, 2004, pp. 181-193.

${ }^{3}$ Véase, por ejemplo, Zaki Laidi, "BRICs: Sovereignty Power and Weakness", International Politics, vol. 49, núm. 5, 2012, pp. 614-632; y Ramesh Thakur, The United Nations, Peace and Security, Cambridge, University Press, 2006. 
desarrollo sobre la cuestión de la intervención militar colectiva. ${ }^{4}$ Según Volker Gutenkunst, la gran mayoría de los Estados del Sur apoya las intervenciones que se deciden en el Consejo de Seguridad por unanimidad y en respuesta a una petición del Estado en cuestión. Por el contrario, varios de ellos se reservan cuando el Estado en cuestión no hizo una solicitud, y más aún si no hay autorización del Consejo de Seguridad. ${ }^{5}$ Así, la mayoría se opuso a la Guerra de Iraq en 2003, criticó la forma de intervención en Libia en 2011 y se muestra perpleja ante el proyecto de operación en Siria ( $c f$. tablas).

Esta diversidad nos invita a relativizar la tesis soberanista y a analizar las motivaciones que llevan a los gobernantes del Sur a apoyar o rechazar los proyectos de intervención militar discutidos en Naciones Unidas.

Este estudio se inscribe en el análisis de los fundamentos de la toma de decisiones en política exterior, aplicado a países del Sur, en caso de intervenciones militares colectivas. El enfoque poliheurístico de Foreign Policy Analysis, que Alex Mintz ha trabajado principalmente, se demuestra útil pues permite conjugar distintos factores (el porqué y el cómo de la toma de decisiones). ${ }^{6} \mathrm{Se}-$ gún este mecanismo, para pronunciarse, los que deciden toman en cuenta múltiples criterios cuyo respectivo peso fluctúa en función del caso. Si una decisión se muestra inaceptable para una dimensión, será desechada. La decisión tampoco depende por completo de un proceso racional: cuentan las representaciones de los actores en el poder; las contingencias alteran las variables más estructurales. El enfoque poliheurístico tiene la virtud de autorizar la reflexión compleja y la inclusión de factores paradójicos: en

${ }^{4}$ Oliver Stuenkel, "The BRICs and the Future of R2P”, Global Reponsability to Protect, vol. 6, núm. 1, 2014, pp. 3-28; y Mohammed Ayoob, "Third World Perspectives on Humanitarian Intervention and International Administration", Global Governance, vol. 10, núm. 1, 2004, p. 99.

${ }^{5}$ Volker Gutekunst, "Developing Countries and the Legitimacy of Military Intervention 1990-2009”, tesis de maestría, Relaciones Internacionales, IEP de ParísFreie Universität de Berlín, 2009.

${ }^{6}$ Alex Mintz (comp.), "The Poliheuristic Theory of Foreign Policy Decision Making”, Journal of Conflict Resolution, vol. 48, núm. 1, 2004, pp. 3-126. 
nuestro caso, el equilibrio entre la defensa del principio de soberanía y el pragmatismo impuesto por otros objetivos de la política exterior.

Este trabajo analiza varias intervenciones militares discutidas en el Consejo de Seguridad y comentadas en la Asamblea General, dado que este tipo de operaciones simboliza la ruptura de la soberanía estatal. Se basa en el análisis de los votos y de sus justificaciones, con ayuda de bibliografía gris. ${ }^{7}$ Con países del Sur nos referimos a los Estados en desarrollo de África, América Latina y el Caribe, Asia y Medio Oriente según la definición propuesta en la introducción. Las intervenciones en Afganistán en 2001, Iraq en 2003, Libia en 2011 y la parálisis frente a la situación siria desde 2012 constituyen los principales casos de estudio. Se optó por concentrarse en los ejemplos que incluían un debate sobre el recurso al capítulo vir de la Carta de las Naciones Unidas, sin solicitud previa del Estado en cuestión. ${ }^{8}$ Además, esos casos presentan un interés doble: comparar las reacciones diferenciadas del mundo en desarrollo ante dos intervenciones en un contexto similar -guerra contra el terrorismo y violación de los derechos humanos- e ilustrar los debates creados por estas dos "nuevas" amenazas contra la paz y la seguridad internacionales. De esta forma, se nutre la reflexión sobre la evolución de las posibles lecturas del derecho internacional público y de la práctica de intervención desde el punto de vista de los actores estatales del Sur.

Es preciso contextualizar con el fin de explicar nuestra propia lectura de los casos antes de pasar a la interpretación de las posiciones del Sur. Al día siguiente de los atentados del 11 de septiembre de 2001, el Consejo de Seguridad vota por unanimidad la Resolución 1368, que califica tales actos de amenaza contra la paz y la seguridad internacionales. El texto evoca el derecho a la legítima defensa. ${ }^{9}$ Algunos especialistas consideran que la resolución

${ }^{7}$ Los documentos de la onU se designan según las signaturas utilizadas por la organización: resolución (RES) y proceso verbal (PV) del Consejo de Seguridad (s) y de la AGNU (AG).

${ }^{8}$ Estudios previos han demostrado que el consentimiento de la parte afectada provoca el apoyo casi unánime de los países del Sur. Volker Gutekunst, op.cit.

${ }^{9}$ S/RES/1368 (2001). 
no da luz verde a Estados Unidos para intervenir en Afganistán a la cabeza de una coalición internacional. ${ }^{10}$ No obstante, la unanimidad del voto aunada a las pocas reacciones en la Asamblea General ${ }^{11}$ se ha interpretado como una aceptación política de la operación.

La cuestión iraquí surge de la lucha contra el terrorismo dirigida por la administración de George W. Bush. Desde la invasión de Kuwait en 1990, el Iraq de Saddam Hussein reta a la comunidad internacional en un juego de aceptación y evasión de las reglas del Consejo de Seguridad. La Resolución 1441 se adopta por unanimidad el 8 de noviembre de 2002, ${ }^{12}$ pero presenta cierta ambigüedad. ${ }^{13}$ Decididos a actuar, Estados Unidos, Gran Bretaña y España intentan en vano obtener un segundo texto más explícito. Frente a la amenaza de veto de Francia y Rusia, y a la falta de apoyo más general, se retira el segundo proyecto de resolución. El 20 de marzo, una coalición internacional ad hoc lanza la operación Libertad Iraquí, sin fundamento legal, aspecto que gran parte del Sur desaprueba. ${ }^{14}$

Lo mismo sucede con respecto a la evolución de los levantamientos populares que atraviesa el mundo árabe desde fines de 2010, en particular Libia y Siria. A mediados de febrero de 2011, la represión de una manifestación en Bengasi transforma el conflicto en insurrección armada. La cuestión libia entra a la onu por las puertas del Consejo de Derechos Humanos, gracias a la diplomacia activa de países como Qatar y Arabia Saudita, de la Liga Árabe, de la Unión Africana (UA) y de la entonces Organización

${ }^{10}$ Olivier Corten y François Dubuisson sostienen que la Carta prevé únicamente la aplicación de la legítima defensa en conflictos interestatales. La Resolución 1368 es mucho más general. "La guerre 'anti-terroriste' engagée par les États-Unis a-t-elle été autorisée par le Conseil de sécurité?”, Journal des Tribunaux, año 120, núm. 6034, 2001, pp. 890-893.

${ }^{11}$ De los 29 países en desarrollo que se manifiestan, 17 apoyan la intervención en Afganistán. Volker Gutekunst, op. cit., p. 48.

${ }^{12}$ S/RES/1441 (2002).

${ }^{13}$ Delphine Placidi-Frot, “1441 (2002): La situation entre l'Iraq et le Koweït”, en Mélanie Albaret et al., (comps.), Les grandes résolutions du Conseil de sécurité des Nations Unies, París, Dalloz, 2012, pp. 321-322.

${ }^{14}$ De los 68 países en desarrollo que toman una postura en la Asamblea General, 53 se oponen a la intervención en Iraq. Volker Gutekunst, op. cit., pp. 55-61. 
de la Conferencia Islámica (oci). El 26 de febrero, el Consejo de Seguridad adopta por unanimidad la Resolución 1970. El texto menciona la "responsabilidad de proteger a su población" y hace alusión al capítulo viI, recurre a la Corte Penal Internacional e impone otras medidas restrictivas. ${ }^{15}$ Como el régimen no cambió de actitud, se vota la Resolución 1973, esta vez con cinco abstenciones (Alemania, Brasil, China, la India y Rusia). Se trata de la primera "consagración operacional"16 de la responsabilidad de proteger, pues el Consejo refuerza el régimen de sanciones y autoriza el uso de la fuerza armada. Sin embargo, excluye "todo despliegue de fuerzas de ocupación extranjeras" en territorio libio. ${ }^{17}$ Los miembros de la Organización del Tratado del Atlántico Norte (OTAN), más Qatar, consideran que esta resolución constituye un fundamento legal para su intervención. La interpretación del documento suscita debate: la Liga Árabe, la Unión Africana y los países emergentes -Brasil, China, la India e incluso Sudáfrica, que votó en favor del texto- denuncian que la misión acordada en la Resolución 1973 rebasó los límites.

Esta gestión de la crisis libia sienta un precedente de peso en las discusiones sobre la cuestión siria. Manifestantes se oponen al gobierno de Bashar al-Assad desde principios de 2011; frente a la represión del régimen, los oponentes se militarizan progresivamente. El Consejo de Seguridad se paraliza por las disensiones entre los miembros, incluidos los del Sur. Una vez más la Liga Árabe y algunos actores individuales se muestran activamente favorables a una intervención mientras que otros socios, como Sudáfrica, China, la India y Pakistán ahora se oponen a cualquier utilización de la fuerza armada. Así, se han bloqueado todos los proyectos de resolución del Consejo que implican sanciones o la remisión a la Corte Penal Internacional. ${ }^{18} \mathrm{~A}$ la inversa, se pudieron adoptar dos resoluciones sobre el envío de una misión de observación. ${ }^{19}$ El

$15 \mathrm{~S} / \mathrm{RES} / 1970(2011) * * *$.

16 Philippe Lagrange, "1674 (2006): Protection des civils dans les conflits armés”, en Mélanie Albaret et al., op. cit., p. 457.

17 S/RES/1973 (2011)*.

18 2011/612, 2012/77, 2012/538 y 2014/348

${ }^{19}$ S/RES/2042 (2012) y S/RES/2043 (2012). 
acuerdo ruso-estadounidense de septiembre de 2013 con miras a impedir el recurso a las armas químicas permitió que se votara la Resolución 2118 y, posteriormente, la 2209 el 6 de marzo de 2015. Asimismo, frente a la degradación de la situación humanitaria y al surgimiento del Estado Islámico en Iraq y el Levante, se logró un consenso. ${ }^{20}$

El análisis de las posturas de los países del Sur en los cuatro casos anteriores prohíbe cualquier generalización. Apoyar o rechazar una operación es una elección eminentemente política, en ningún caso, un automatismo de principios. Las motivaciones fluctúan en función de los actores y los casos. Por ejemplo, China se opone a cualquier acción en Siria -por lo menos hasta principios del 2015-, pero se mostró mucho menos hostil ante la operación de la onu en Afganistán. Sesenta y ocho países cambian de postura en el transcurso de tres votaciones en la Asamblea General de las Naciones Unidas entre 2011 y 2012 con respecto a Siria ( $c f$. tabla 2, incluyendo ausencias). De los cuatro casos seleccionados, el de Iraq parece representar una excepción por la relevancia que cobró el rechazo. Por lo tanto, la comprensión de los fundamentos de la toma de decisiones no puede ser sino multicausal y contingente. Los representantes de los Estados del Sur cambian de postura en función del caso, al igual que la interacción de los factores que animan la toma de decisiones.

El objetivo de este artículo es entender cómo interactúan los principales factores de motivación en ciertas circunstancias con el fin de demostrar la complejidad de los posicionamientos del Sur frente a la intervención militar colectiva. Tres tipos de variantes, a veces opuestas, influyen en la determinación de las posturas del Sur. Primero, los principios de no intervención y prohibición del recurso a la fuerza representan un escudo protector para países desfavorecidos por la distribución del poder a escala mundial, que además han vivido, en su gran mayoría, experiencias traumáticas de intervenciones, sufridas o realizadas. Sin embargo, los

${ }^{20}$ Sobre cuestiones humanitarias: S/RES/2139 (2014), S/RES/2165 (2014) y S/RES/2191 (2014); y frente a las organizaciones terroristas: S/RES/2170 (2014) y S/RES/2199 (2015). 
proyectos de operaciones militares colectivas al mismo tiempo pueden servir a los intereses de los Estados del Sur de tres formas: los objetivos que buscan en su relación con las grandes potencias, particularmente con Estados Unidos; sus aspiraciones regionales y la búsqueda por parte de gobiernos de conservar el poder; por último, la evolución del contexto internacional induce el cambio de las posturas, aunque se trata del mismo marco de acción (lucha contra el terrorismo y el recurso a la responsabilidad de proteger). De manera general, la defensa del principio fundador de la no intervención, tan relativa como sea, se cuestiona con la introducción de nuevas exigencias en la agenda internacional, como la defensa de los derechos humanos, que los países del Sur no pueden excluir de su política exterior.

\section{LA NO INTERVENCIÓN COMO PROTECGIÓN}

El conjunto de los Estados del Sur no desperdicia ninguna ocasión para recordar que no se puede aceptar una intervención militar fuera del marco del capítulo viı de la Carta, que sólo el Consejo de Seguridad está habilitado a poner en práctica. ${ }^{21}$ Sus socios del Norte también buscan inscribir sus acciones en este marco. Sin embargo, las motivaciones que originan este proceder común divergen. Para los segundos, la legalidad es esencialmente fuente de legitimidad. Para los países del Sur, el marco legal de la intervención militar sirve además de protección frente al desequilibrio de la distribución del poder a escala global. La historia está ahí para recordarles las consecuencias nefastas de la falta de control cuando el poder se ha ejercido en su contra.

21 Este argumento se fortalece en los periodos de tensión: la sesión abierta del Consejo de Seguridad, a petición del Movimiento de los No Alineados, en octubre de 2002 sobre la situación entre Iraq y Kuwait se transforma en una argumentación contra la guerra y en favor de que la onu se ocupe de cualquier recurso a la fuerza. S/PV.4625 y reanudaciones 1,2 y 3 (2002). 


\subsection{El derecho internacional, escudo de los vulnerables}

\subsubsection{Una igualdad jurídica preciosa}

La gran mayoría de los países del Sur sufren cierta vulnerabilidad en múltiples aspectos, particularmente en materia de paz y de seguridad internacionales. La repartición del poder militar, globalmente, les es desfavorable, ${ }^{22}$ lo cual tiene consecuencias significativas sobre su capacidad para protegerse y participar en proyectos de operaciones militares colectivas. ${ }^{23}$ Desde entonces, la soberanía, sin borrar la estructura asimétrica del sistema internacional, sirve no obstante como muralla jurídica contra las voluntades de los más poderosos. De ahí se deduce la igualdad jurídica entre Estados y la prohibición a inmiscuirse en los asuntos internos.

En el campo de la seguridad, la onU sigue siendo la única garante de la aplicación del derecho internacional. Desde 1969, Robert Keohane percibió tres atributos de las organizaciones internacionales que favorecen a los Estados del Sur: la igualdad formal, la seguridad y la restricción de las grandes potencias. ${ }^{24} \mathrm{El}$ corolario lógico de este uso del multilateralismo radica en la aversión compartida entre los países del Sur ante las prácticas unilaterales, símbolo de la ruptura del escudo y de la expresión del poder desigual.

${ }^{22}$ En 2013, Estados Unidos acumuló 37\% del gasto militar mundial, http:/ / books.sipri.org/product_info?c_product_id=476\# (26/09/2014).

${ }^{23}$ El lugar desfavorable de los países en desarrollo a escala global entra recurrentemente en los trabajos de académicos, para explicar sus estrategias multilaterales. Caso de Sudáfrica: Folashadé Soulé-Kohndou, Puissances émergentes et multilatéralisme: le cas de l'Afrique du Sud (1999-2008), París, L'Harmattan, 2010, p. 30. Caso de Brasil: Maria Regina Soares de Lima y Mónica Hirst, "Brazil as an Intermediate State and Regional Power: Action, Choice and Responsibilities", International Affairs, vol. 82, núm. 1, 2006, p. 28. Caso de China: Rosemary Foot, "Chinese Strategies in a US-Hegemonic Global Order: Accomodating and Hedging”, International Affairs, vol. 82, núm. 1, 2006, p. 77. Caso de México: Ana Covarrubias, "Los derechos humanos en la política exterior de México: ¿en defensa propia o de los valores liberales?”, en Ana Covarrubias (comp.), Temas de política exterior, México, El Colegio de México, 2008, p. 327.

${ }^{24}$ Robert O. Keohane, “Lilliputians' Dilemmas: Small States in International Politics”, International Organization, vol. 23, núm. 2, 1969, pp. 291-296. 
El cambio de postura de la mayoría de los Estados del Sur entre las intervenciones en Afganistán y en Iraq, ambas inscritas en la lucha contra el terrorismo, constituye un ejemplo ya clásico, todavía útil. En 2001, la Asamblea General adopta por consenso una resolución que condena los actos terroristas y apoya a Estados Unidos; el Consejo de Seguridad vota por unanimidad la Resolución 1368 y se calla luego de la operación lanzada en consecuencia ( $c f$. tablas). $\mathrm{Al}$ contrario, el caso iraquí se muestra mucho más problemático para la mayoría de los países del Sur. ${ }^{25}$

En el intervalo, Estados Unidos presenta la doctrina de la guerra preventiva ${ }^{26}$ que autorizaría una intervención en caso de "amenaza inminente", y que cristaliza los temores de los países del Sur, de los cuales sólo una minoría (quince en total; nueve después de haber cambiado de opinión $)^{27}$ se deja convencer. A pesar de las presiones diplomáticas, los miembros no permanentes del Sur -salvo Colombia- se unen a Francia, Alemania y Rusia en el rechazo a intervenir antes de votar una segunda resolución. ${ }^{28}$ A fines de febrero de 2003, la Declaración final de la XIII Cumbre de los No Alineados estipula "el papel vital de Naciones Unidas en el mantenimiento de la paz y la seguridad internacionales y en el fortalecimiento de la cooperación internacional" y "reitera su firme condena a toda acción militar unilateral, incluyendo aquéllas llevadas a cabo sin la debida autorización del Consejo de Seguridad de Naciones Unidas". ${ }^{29}$

Las posturas de Chile y de México son particularmente ilustrativas. Miembros no permanentes cuando la intervención en Iraq,

${ }^{25}$ Cf. tablas y balance de las declaraciones propuesto por Volker Gutekunst (nota 11).

${ }^{26}$ National Security Strategy, publicado en septiembre de 2002.

${ }^{27}$ Volker Gutekunst, op. cit.

28 Se trata de Angola, Camerún, Chile, Guinea, México y Pakistán. Alexandra Novosseloff, "The Role of Emerging Countries in the United Nations", en Christophe Jaffrelot (comp.), Emerging States: the Wellspring of a New World Order, París, Presses de Sciences Po, 2008, p. 264.

29 \$5 del Documento Final de la XIII Conferencia de los Jefes de Estado o de Gobierno del Movimiento de los No Alineados, Kuala Lumpur, 24-25 de febrero de 2003, http://www.nam.gov.za/media/030227e.htm, consultado el 24 de septiembre de 2014. 
se muestran reacios a una intervención a pesar de las importantes negociaciones bilaterales mantenidas con Estados Unidos, como la que desembocó en el tratado de libre comercio con Chile tras una década de negociación. A pesar de esta restricción, prima el compromiso con el derecho internacional público. En 2011 -no miembros del Consejo en ese entonces- se muestran de inicio favorables a la operación libia, puesto que es acorde con la Carta. ${ }^{30}$

El papel doblemente protector del derecho internacional y del marco multilateral funda la reticencia de los países del Sur frente a las interpretaciones más laxas de sus socios del Norte, Estados Unidos y Europa Occidental en particular.

\subsubsection{Los intentos de los más poderosos por implementar el derecho}

La legalidad de la intervención no se limita a la adopción de una resolución; queda por determinar su interpretación. Este es el caso de la Resolución 1441 (2002) sobre Iraq y la 1973 (2011) sobre Libia. La mayoría de los países del Sur no comparten ni la lectura propuesta por Estados Unidos en 2002, ni la de la OTAN en 2011. Se las considera al servicio de los más poderosos y no una defensa de la paz y la seguridad internacionales. Aquí se ve el dilema de asimetría del poder, dado que son los que tienen mayor capacidad militar los que se permiten desviarse de la regla normativa.

Los representantes estadounidenses en vano buscaron convencer sobre la legalidad de la intervención en Iraq de 2003 a partir de resoluciones preexistentes: la 1441 (2002), que no usa el vocabulario comúnmente admitido: "graves consecuencias" y no "todas las medidas necesarias"; y la 687 (1991), que sin embargo acaba con "decide seguirse ocupando de la cuestión y dar los pasos que sean necesarios". ${ }^{31}$

30 "América Latina/Libia: división de opiniones a favor y contra a la acción militar", Efe, 20 de marzo de 2011; y "Respalda Calderón acción militar contra Libia”, Proceso, 29 de marzo de 2011.

31 S/RES/1441 (2002) y S/RES/687 (1991). Varios países miembros, no obstante, habían hecho explícita la opinión de que la resolución no autoriza- 
Con respecto a Libia, las críticas de una vasta mayoría de países del Sur se refieren tanto al contenido como a la ejecución de la Resolución 1973. La India, China y Brasil se abstuvieron en el momento de la adopción del texto, reiterando las reservas emitidas en la Asamblea General. Se presencia el giro de las posturas del Sur luego del inicio de la operación, ${ }^{32}$ por una parte en razón del control total de la OTAN sobre la ejecución y, por otra, a causa de los bombardeos que facilitaron la caída del régimen de Muamar Gadafi. La OTAN secundó de cierta forma a la Unión Africana y la Liga Árabe, que habían tomado iniciativas. Como recuerda una de las consideraciones de la Resolución 1973, el Consejo de Paz y de Seguridad de la Unión Africana creó un comité ad hoc de alto nivel para Libia, el 10 de marzo, cuya primera reunión se anunció para el 19, es decir, dos días después de la votación del texto. ${ }^{33}$ Los bombardeos de la OTAN comienzan el mismo día, sin dar oportunidad al comité ad hoc de la Unión Africana de llevar a cabo su misión. ${ }^{34}$

Si la Liga Árabe decidió desde el 12 de marzo exigir la imposición de una zona de exclusión aérea, las múltiples acciones de la OTAN la sobrepasaron claramente: ${ }^{35}$ lanzamiento en paracaídas de armas, contacto con los opositores y bombardeos. Para la mayoría del Sur, la operación en ningún caso debía apuntar hacia el derrocamiento del régimen en turno. Por lo tanto, el apego al principio de no intervención sirve a los intereses de los países del Sur, pero

ba el recurso a la fuerza. S/PV.4644 (2002): Camerún, China, Colombia, México, Siria.

3272 horas después del lanzamiento de la operación, la Liga Árabe retira su apoyo, seguida por la UA y la ocI. Bertrand Badie, "1973 (2011): Jamahiriya Arabe Libyenne”, en Mélanie Albaret et al., op. cit., p. 562.

${ }^{33}$ Véase el comunicado de la UA: http://www.au.int/fr/sites/default/files/ PRESS_RELEASE_FR_17_MARCH_2011_PSD_THE_AFRICAN_UNION_AD_ HOC_HIGH_LEVEL_COMMITTEE_ON_LIBYA_MEETS_IN_NOUAKCHOTT. pdf, consultado el 27 de septiembre de 2014.

${ }^{34}$ Delphine Lecoutre, "La gestion de la crise libyenne par l'Union Africaine. Chronique d'une impuissance annoncée”, Laboratoire de l'Irsem, 2012 (Ministère français de la défense, núm. 11, pp. 18-19).

${ }^{35}$ Varios representantes subrayan esta diferencia en la explicación de su voto. S/PV.6498: Sudáfrica, Líbano, Nigeria. Otros expresan temores: Brasil, la India. 
también se vincula a que varios de estos Estados han sufrido experiencias traumáticas de intervención.

\subsection{Intervención y Sur: una historia tormentosa}

La mayoría de los llamados países del Sur han sido víctimas directas $\mathrm{u}$ observadores de intervenciones en su entorno. Estos actos se han vivido como "humillaciones por negación de igualdad". ${ }^{36}$ China quedó profundamente marcada por los tratados desiguales. ${ }^{37}$ Las posturas defensivas de los representantes latinoamericanos sobre el tema de la intervención militar también están ligadas a los traumas de la Guerra Fría, que constituyen una especie de "marco doctrinario". ${ }^{38}$ Heraldo Muñoz, ministro de Relaciones Exteriores de Chile desde marzo de 2014 y diplomático aguerrido, escribió en un testimonio personal: "Los miembros latinoamericanos del Consejo de Seguridad de 2003 sabían lo que significaba la intervención extranjera. [...] Chile, una democracia de larga duración, fue blanco de un intento de golpe de Estado respaldado por la cia y de una furiosa campaña desestabilizadora por parte de la administración de Richard Nixon debido a la elección democrática del candidato socialista Salvador Allende como presidente de la nación". ${ }^{39}$

Estas experiencias resultaron amargas y generaron escepticismo en varios países del Sur en cuanto a la oportunidad que representa-desde su punto de vista-la intervención militar como método de resolución de conflictos. El argumento sobre la ineficacia de recurrir a la fuerza fundamenta las reticencias expresadas por esos actores al momento de los debates sobre nuestros cuatro casos, independientemente de su postura con respecto al proyecto examinado. Así, al momento de la operación en Afganistán, cuatro de los ocho miembros del Sur en el Consejo de Seguridad -Bangladesh,

${ }^{36}$ Bertrand Badie, Le temps des humiliés, París, Odile Jacob, 2014.

37 Allen Carlson, "Helping to Keep the Peace (Albeit Relunctantly): China's Recent Stance on Sovereignty and Multilateral Intervention”, Pacific Affairs, vol. 77, núm. 1, 2004, p. 11.

${ }^{38}$ Mohammed Ayoob, op. cit., p. 109.

${ }^{39}$ Heraldo Muñoz, A Solitary War, Golden, Col., Fulcrum, 2008, p. 163. 
China, Mali, Túnez-, sin desaprobar la decisión, insisten en la estrategia postconflicto, etapa necesaria para el éxito de la intervención. ${ }^{40}$ Igualmente, cuando se votó la Resolución 1973, sobre la violencia que sufrió su país, el representante de Líbano deduce que no podría preconizar el recurso a la fuerza para cualquier país y espera que la decisión del Consejo tenga un efecto disuasivo. Por último, la representante brasileña justifica la abstención de su país por el escepticismo con respecto al uso de la fuerza. ${ }^{41}$

No sólo las intervenciones sufridas provocaron el trauma, también las repercusiones de operaciones llevadas a cabo por los países del Sur. Este es principalmente el caso de Sudáfrica. En la estela de la transición democrática iniciada en 1991, los gobiernos del Congreso Nacional Africano (CNA) buscaron renovar la imagen internacional del país, manchado por las décadas del Apartheid. Sin embargo, sus primeros intentos de resolución de conflictos regionales los llevaron a una humildad y prudencia mayores. ${ }^{42}$ En septiembre de 1998 Sudáfrica y Botswana intervinieron militarmente en Lesoto para impedir un inminente golpe de Estado, bajo demanda del jefe de gobierno legal. La franca resistencia a su presencia provocó manifestaciones y amplificó la desestabilización de la capital. Esta experiencia se consideró un fracaso. Sumado a otros intentos desafortunados -la crítica del régimen nigeriano luego de la ejecución de opositores en 1995 definida por los socios africanos como "demasiado" occidental-, el episodio de Lesoto transformó la política exterior sudafricana en favor de una más comprometida defensa del respeto a la no injerencia en los asuntos internos de los socios. La "diplomacia silenciosa" que se adoptó con Zimbabue ${ }^{43}$ ilustra esta reconversión.

${ }^{40}$ Volker Gutekunst, op. cit., p. 49.

${ }^{41}$ Para ambos ejemplos: S/PV.6498 (2011).

42 Adekeye Adebajo, Adebayo Adedji y Chris Landsberg, South Africa in Africa: the Post-Apartheid Era, Scottsville, University of KwaZulu-Natal, 2007.

43 Daniel Flemes, "Regional Power South Africa: Co-operative Hegemony Constrained by Historical Legacy", Journal of Contemporary African Studies, vol. 27, núm. 2, 2009, p. 150; y Sandrine Perrot, "Les nouveaux interventionnismes militaires africains. Une redéfinition des conditions de la puissance au Sud du Sahara?”, Politique Africaine, núm. 98, 2005, p. 124. 
La protección que ofrece el derecho internacional, asociada a la experiencia de intervención militar, lleva a los países del Sur a defender el respeto a la soberanía. Hay que constatar, no obstante, que las tomas de postura del Sur no siempre responden a esta lógica. La mayoría apoyó la operación en Afganistán; una minoría la de Iraq; gran parte promovió la de Libia antes de mostrarse más indecisa con respecto a Siria. De hecho, la intervención militar colectiva representa también una herramienta potencial al servicio de los objetivos de la política exterior y la conservación del poder.

\section{LA INTERVENCIÓN COMO MEDIO DE ASCENSO}

El apego a la soberanía choca a veces con otras variables que obligan a los Estados del Sur a relativizar su función protectora, según la lógica poliheurística. El análisis de su diplomacia nos ha permitido extraer tres: los objetivos perseguidos en sus relaciones con las grandes potencias, las ambiciones regionales y la conservación del poder interno.

\subsection{Usos de poder intervencionista al servicio de aspiraciones globales}

Los diferentes grados de rechazo de un proyecto de intervención militar colectiva dependen en gran medida de la relación que se tenga con Estados Unidos.

Entre más tensos sean los lazos bilaterales, mayor será la desconfianza de los Estados del Sur con respecto a las intenciones ocultas de recurrir a la fuerza. La retórica antiimperialista define los argumentos de los países de la Alianza Bolivariana para los Pueblos de Nuestra América (ALBA) frente a las crisis libia y siria; ${ }^{44}$ y

${ }^{44}$ Miembro del Consejo de Seguridad en 2015 y 2016, Venezuela es el único país que se abstuvo al votar la Resolución 2209 del 6 de marzo de 2015 sobre Siria. La explicación del voto remite a problemas de procedimiento y al rechazo del recurso a la fuerza (S/PV.7401). La Revolución Bolivariana apoya explícitamente al régimen de Bashar al-Asad. Ecuador muestra más matices, critica a Estados Unidos sin olvidar la protección de los derechos humanos (A/65/PV.76). 
los votos de Corea del Norte y de Irán se explican por las tensiones con la primera potencia. ${ }^{45}$ Las malas relaciones con esta última influyen en la percepción de la intervención, más allá de su legalidad. Aunque la influencia del factor ideológico no sea automática, los aspirantes a los papeles de jugadores globales, al igual que los más radicales, critican que los más grandes recurran a la fuerza.

Los BRICS, por ejemplo, están en una posición más delicada: intentar resistirse a Estados Unidos, sin irritarlo, con el fin de obtener un mejor lugar en la toma de decisiones a escala mundial. ${ }^{46} \mathrm{Se}$ trata de encontrar un equilibrio entre la promoción de la reforma de las instituciones multilaterales, en particular del Consejo de Seguridad para Brasil ${ }^{47}$ y la India, sin provocar un bloqueo estadounidense. Así, la cooperación que ofrecieron China y la India luego de la intervención en Afganistán se tradujo en el Norte como un acto de responsabilidad. De este modo, China busca no agudizar el sentimiento de "miedo" que suscita su ascenso global; mientras que la India intenta establecer una relación más fluida con Estados Unidos. ${ }^{48} \mathrm{El}$ año 2011 presentó una configuración interesante, ya

${ }^{45}$ Denuncian principalmente las intenciones egoístas de Estados Unidos. Sobre Iraq: Irán, Libia, Malasia, Vietnam, Zimbabue (S/PV.4625, reanudaciones 1 y 2). Sobre Libia: Cuba, Nicaragua, Venezuela (A/65/PV.76). Sobre Siria: A/66/ PV.97 (2012); A/66/PV.124: Bolivia, Corea del Norte, Venezuela.

${ }^{46}$ Los intereses bilaterales entre los emergentes y estos países, aunque hayan aumentado en el transcurso de la última década y se hayan tomado en cuenta, no son la variable más influyente durante estas dos crisis.

Mônica Herz y Lucas Pérez Florentino, "Os BRics e as revoltas no Oriente Médio e Norte da África”, BRICs Policy Center, 2011, p. 6 (Policy Brief).

47 Celso Amorim, Ministro de Relaciones Exteriores durante la presidencia de Lula, reconoció que la posición de Brasil sobre Iraq sirvió para proyectar al país en la escena mundial en cuestiones de seguridad. Subraya igualmente la intención de mantener buenas relaciones con Estados Unidos. Celso Amorim, "Primeiros passos: Iraque”, en Breves narrativas diplomáticas, São Paulo, Benvirá, 2013, pp. 15-33.

48 Caso de China: Jan Rowinsli, "Position of China Regarding September 11", Polish Quarterly of International Affairs, vol. 11, núm. 1, 2002, pp. 36-37. Caso de la India: Jean-Luc Racine, "Quête de puissance, multipolarité et multilatéralisme”, en Christophe Jaffrelot (comp.), New Delhi et le monde, París, Les Presses de Sciences Po, 2011, p. 39. 
que el conjunto de los BRICS estaba reunido en el Consejo. Los debates que generaron los proyectos de intervención en Libia y Siria sentaron un contexto propicio para denunciar los malos funcionamientos del organismo mediante sus abstenciones. ${ }^{49}$ Este tipo de proyecto refuerza la exigencia de reformas, como lo demostró el caso iraquí. ${ }^{50}$

Por último, una tercera categoría de actores opta por el apoyo a las intervenciones propuestas por Estados Unidos para usar sus buenas relaciones bilaterales como trampolines para el plano internacional. Tal fue principalmente el caso de Siria y de Qatar con la guerra en Iraq. El régimen de Bashar al-Asad vota la Resolución 1441 y, aunque se opone a la intervención, los lazos con Washington se reanudan desde 2003, siempre en el mismo contexto. ${ }^{51}$ Asimismo, que Qatar albergara al comando central estadounidense durante la operación iraquí impulsó el surgimiento diplomático de ese país, en detrimento de su vecina Arabia Saudita. ${ }^{52}$

\subsection{Alejar a los rivales y posicionarse de manera estratégica: los dilemas regionales}

La variable regional parece un catalizador del intervencionismo. Cuando estallan los conflictos en Medio Oriente y Asia Central, los Estados vecinos no se manifiestan en defensa de la soberanía. Aunque desprovistos de capacidades de impacto similares a las

49 Victor Countinho Lage, "Os BRICs nas resoluções sob o capítulo VII da Carta da Organização das Nações Unidas após a Guerra Fria”, BRICs Policy Center, 2011 (Policy Brief, p. 8).

${ }^{50} \mathrm{~S} / \mathrm{PV} .4625$, reanudaciones 1 y 2: Sudáfrica, Brasil, Cuba, la India, Jamaica, Libia, Sudán.

${ }^{51}$ Marta Tawil Kuri, "Siria: Estabilidad interna y poder regional en un entorno conflictivo", en Luis Mesa Delmonte (comp.), Las relaciones exteriores de Siria, México, El Colegio de México, 2013, p. 35.

${ }^{52}$ Sin que eso signifique la alineación automática con la postura estadounidense, como recuerda la crisis siria. Lina Khatib, "Qatar's Foreign Policy: the Limits of Pragmatism”, International Affairs, vol. 89, núm. 2, 2013, p. 421; y Mikail Barah, "Le paradoxe diplomatique du Qatar comme moyen d'accès à la consécration”, Revue Internationale et Stratégique, núm. 69, 2008, pp. 31-41. 
del Norte, los intentos por introducir elementos egoístas en las soluciones propuestas no son menores entre los representantes del Sur. En este sentido, las repercusiones de una intervención en su entorno inmediato influyen en la decisión, ${ }^{53}$ a veces en favor de recurrir a la fuerza. La lógica de competencia entre la India y Paquistán por un lado, y entre Arabia Saudita y Qatar por el otro, ilustró lo anterior en relación con las intervenciones en Afganistán, Libia y Siria.

Así fue instrumentalizada la guerra contra el terrorismo por la India y Paquistán en su estrategia regional. Cada uno escogió aliarse con Estados Unidos tanto para evitar el surgimiento de un régimen favorable al otro en Afganistán, ${ }^{54}$ como para promover su visión del conflicto en Cachemira, sin éxito en el segundo punto. ${ }^{55}$ Paquistán, en busca de reconocimiento y en una especie de arrepentimiento por haber mantenido contacto con los talibanes y llevado a cabo pruebas nucleares, se presenta como aliado indispensable en la lucha contra al-Qaeda, y lo usa para alejar a la India, rechazando su participación en la coalición (al igual que la de Israel) ${ }^{56}$ Frente a las contradicciones paquistaníes -mantener vínculos con los talibanes-, la India se posiciona entonces como socio estratégico más convincente para Estados Unidos. ${ }^{57}$

Las crisis libia y siria, por su parte, alimentaron la competencia entre Arabia Saudita y Qatar. A pesar del apoyo común a la intervención, sus objetivos divergen. Así, el apoyo financiero gu-

${ }^{53}$ Mohammed Ayoob, op. cit., p. 105.

${ }^{54}$ Christine C. Fair, The Counterterror Coalitions: Cooperation with Pakistan and India, Santa Monica, RAND Project Air Force, 2004, p. 19.

${ }^{55}$ Paquistán aprovecha los debates sobre el proyecto de intervención en Iraq para denunciar a la India en Cachemira. S/PV.4625.

56 Shahid Amin, "Post 9/11 Developments in Pakistan's Foreign Policy", en Pakistan's Foreign Policy: A Reappraisal, Karachi, Oxford University Press, $2^{\text {a }}$ ed., 2010, pp. 315-319; y Pawel Milewski, "Pakistan and India and the Events of September 11", Polish Quarterly of International Affairs, vol. 11, núm. 1, 2002, pp. 124-125.

${ }^{57}$ La India también tenía que disculparse por sus pruebas nucleares. Christophe Jaffrelot, "Chapitre introductif. Les quatre points cardinaux de la diplomatie indienne: le régional et le global, l’idéalisme et le réalisme”, en Christophe Jaffrelot (comp.), op. cit., 2008, p. 24. 
bernamental y las armas no se dirigen a las mismas facciones. Qatar es más cercano a los Hermanos Musulmanes. ${ }^{58} \mathrm{Y}$ cada uno busca moldear a su favor el futuro de los países intervenidos y aprovechar, en el caso de Siria, el cambio en el equilibrio de fuerzas regionales con la caída de un aliado de la enemiga revolución islámica iraní. ${ }^{59}$ Ambos fueron determinantes para el posicionamiento de la Liga Árabe ${ }^{60}$ y la promoción de resoluciones, a pesar de sus intereses económicos en esos países. ${ }^{61}$ Qatar era el único país no miembro de la otAn en la operación libia. Arabia Saudita, elegida por primera vez como miembro no permanente del Consejo de Seguridad, se negó a tomar el asiento en protesta contra la inacción del órgano frente la crisis siria. ${ }^{62}$ La búsqueda de liderazgo regional de estos dos actores los obliga a apoyar prácticas intervencionistas, tanto a escala local como en el marco de la ONU.

Finalmente, la ausencia de proximidad geográfica facilita la lectura de las intervenciones militares a partir de los principios fundadores (derecho internacional como escudo e intervención ineficaz). Los países latinoamericanos hostiles a la intervención pueden oponerse a los proyectos iraquíes, libios y sirios con más facilidad que Qatar y Arabia Saudita. Igualmente, a China y la India les cuesta menos ser reticentes ante estos tres casos que ante su vecino Afganistán. Así como los dilemas regionales constituyen un elemento clave en el posicionamiento de los países del Sur frente a los proyectos de intervención militar colectiva, los factores internos parecen determinantes, aunque equívocos.

58 Alejandra Galindo, "Los desafíos de los países del Consejo de Cooperación del Golfo ante la crisis de Siria: Arabia Saudita y Qatar", en Gilberto Conde (comp.), Levantamiento popular y guerra civil en Siria: repercusiones internacionales, México, El Colegio de México, por publicarse.

${ }^{59}$ David Rigoulet-Roze, "Le Qatar : un paradoxe géopolitique et une anomalie géoéconomique”, Géoéconomie, vol. 3, núm. 62, 2012, pp. 53-66.

${ }^{60}$ Que se había opuesto a la guerra en Iraq. S/PV.4625, reanudación 1, p. 8.

${ }^{61}$ Alejandra Galindo, op. cit.

62 "Carta de fecha 12 de noviembre de 2013 dirigida al Secretario General por el Representante Permanente de la Arabia Saudita ante las Naciones Unidas”, A/68/599, 14 de noviembre de 2013 . 


\subsection{La influencia contradictoria de las situaciones internas}

Los cuatro casos de estudio llevan a relativizar de manera significativa el lazo entre principio de no intervención y configuración política interna. En efecto, varios regímenes autoritarios no solamente han apoyado, sino también promovido, proyectos de intervención militar colectiva, por ejemplo, varios países del Golfo con respecto a Libia y Siria; o Paquistán y China a favor de la operación afgana. Esta última participó incluso en la redacción de la Resolución 1368. La influencia del régimen puede sentirse en la retórica empleada para justificar las posturas y evitar que los argumentos utilizados puedan volverse en su contra. ${ }^{63}$ Por el contrario, los dirigentes de todo tipo de régimen buscan sistemáticamente que su formación política se mantenga en el poder, ${ }^{64}$ lo que puede llevarlos en dado caso a escuchar a la opinión pública.

Este elemento se muestra "permisivo" y no dominante en otras variables. ${ }^{65}$ Sucede principalmente en los casos de Arabia Saudita, China y Paquistán, que apoyan las intervenciones dirigidas por Estados Unidos en el contexto de la guerra contra el terrorismo mientras que los ciudadanos demuestran cierta antipatía frente a la potencia ${ }^{66}$ Además, la opinión pública no es unidireccional; por lo tanto, puede contribuir de forma preventiva, disuasiva, pero también catalizadora ${ }^{67}$ La opinión saudí parece igualmente sensible ante la defensa de los sunitas en Siria (contra Bashar al-Asad).

Las motivaciones internas en favor del apoyo a la intervención militar colectiva radican principalmente en la posibilidad de los di-

${ }^{63}$ China no se refiere a la cuestión del régimen en sus intervenciones sobre Libia o Siria.

${ }^{64}$ Bruce Russett, Controlling the Sword: The Democratic Governance of National Security, Cambridge, Harvard University Press, 1990.

${ }^{65}$ Nathalie La Balme, "Opinion publique et politique étrangère: l'évolution du débat”, en Frédéric Charillon (comp.), Politique étrangère, nouveaux regards, París, Presses de Sciences Po, 2002, p. 203.

${ }^{66}$ Esto explica también la débil publicidad del apoyo. Philippe Droz-Vincent, "Les dilemmes des régimes arabes après l'intervention américaine en Irak", Politique Étrangère, vol. 68, núm. 3-4, 2003, p. 556; y Jan Rowinsli, op. cit., p. 34.

${ }^{67}$ Nathalie La Balme, op. cit., p. 207. 
rigentes de obtener apoyo internacional para su proyecto interno. Por ejemplo, la lucha contra el terrorismo ${ }^{68}$ permite al gobierno chino desarrollar acciones contra los separatistas de Xinjiang, destacando sus lazos con movimientos islamistas. Al mismo tiempo, su cooperación aminora las críticas sobre las violaciones de derechos humanos. ${ }^{69} \mathrm{El}$ general Pervez Musharraf aprovechó para obtener el reconocimiento a su gobierno (surgido de un golpe de Estado) y proponer un referéndum en mayo de 2002 para prolongar su mandato ${ }^{70}$ La alineación colombiana con Estados Unidos en este contexto también se vincula con la estrategia de los gobiernos en la lucha contra las Fuerzas Armadas Revolucionarias de Colombia (FARC)..$^{71}$

La incitación al rechazo del recuso colectivo a la fuerza no termina ahí. De inicio, se trata de evitar problemas internos. Ante una población verdaderamente hostil, el general Musharraf no pudo apoyar abiertamente la guerra en Iraq de 2003. ${ }^{72}$ Además, los dirigentes políticos deseaban evitar cualquier efecto mariposa. Las repercusiones regionales de una intervención en Iraq se mencionan de manera casi sistemática durante la sesión abierta del Consejo de Seguridad de octubre de 2002,73 igual que para Libia. China se mostró reticente a intervenir en el contexto de las Primaveras Árabes, igual que después del surgimiento de protestas en su

$68 \mathrm{Al}$ explicar su voto sobre la Resolución 1368 (2001), China subraya que el terrorismo internacional "pone en grave peligro [...] el orden político y económico de los países” (S/PV.4370). Igualmente, al votar la Resolución 2170 de agosto de 2014 sobre la amenaza que representan los grupos terroristas Estado Islámico y Frente al-Nusra, el representante chino se jacta de las sanciones previstas con respecto al uso de internet y de redes sociales ya que "China misma es víctima del terrorismo" (S/PV.7242).

${ }^{69}$ Jan Rowinsli, op. cit., pp. 41-42.

${ }^{70}$ Pawel Milewski, op. cit., pp. 128-129.

71 Sandra Borda Guzmán, "La internacionalización del conflicto armado después del 11 de septiembre: ¿la ejecución de una estrategia diplomática hábil o la simple ocurrencia de lo inevitable?”, Colombia Internacional, núm. 65, 2007, pp. 66-89.

72 Evocó en el Consejo de Seguridad las "preocupaciones del hombre de a pie" (S/PV.4625).

${ }^{73} \mathrm{~S} / \mathrm{PV} .4625$ y reanudaciones 1,2 y 3. 
territorio. ${ }^{74}$ Los regímenes del Golfo también se enfrentaron a demandas de reforma inspiradas por el contexto regional. ${ }^{75}$ Luego, los representantes políticos pueden intentar ganarse el favor de la gente al seguir la tendencia, con el fin de revitalizar su imagen. Las reticencias chilena y mexicana frente al proyecto de intervención en Iraq reflejan asimismo la tendencia mayoritaria de su opinión pública. ${ }^{76}$ La influencia de esta variable, sumada a la defensa del derecho internacional primó sobre la relación bilateral con Estados Unidos.

El posicionamiento de los países del Sur sobre la acción de factores contradictorios a veces se revela delicado. El contexto puede ayudar a inclinar la balanza en favor de una de sus opciones.

\section{El PESO DE LAS CONTINGENGIAS}

Los cambios en el contexto internacional no pasan sin consecuencias sobre las tomas de decisión. Asimismo, la aparición de nuevas temáticas en la agenda internacional, como la protección de los derechos humanos y la responsabilidad de protección, provocan una evolución en el debate sobre el uso de la intervención militar a la que los países del Sur no escapan.

\subsection{Diferentes usos del contexto internacional}

En un estudio original, Gary Goertz se detiene en el papel del contexto internacional como variable integral en la toma de decisiones en política exterior. Identifica tres posibles papeles del contexto:

${ }^{74}$ I-Wei Jennifer Chang, "Chinese Policies on the Arab Spring”, en Robert Mason (comp.), Popular Unrest and Foreign Policy, Basingstoke, Palgrave Macmillan, 2014.

${ }^{75}$ En Qatar se publicó un panfleto Qataris for Reforms y en varios países hubo manifestaciones. Lina Khatib, op. cit., p. 430.

${ }^{76}$ Joaquín Fermandois, "Chile y la Guerra de Irak", Bicentenario, vol. 7, núm. 1, 2008, pp. 45-78; y Olga Pellicer, "Los dilemas de México en el Consejo de seguridad”, en Rafael Fernández de Castro (comp.), En la frontera del imperio, México, Planeta, 2003, pp. 97-99. 
como causa que permite obtener un resultado, como barrera que impide el fin de una acción o como significado cambiante (changing meaning) que implica distintas interpretaciones de cierta regla en función la sociedad y la época. ${ }^{77}$ Aplicados a nuestros casos de estudio, estas tres configuraciones permiten identificar las distintas influencias de las contingencias en la determinación de las posturas del Sur.

La intervención en Afganistán resultó claramente más fácil por el impacto de los atentados del 11 de septiembre. De forma general, la legitimidad de una decisión tomada en el seno de las Naciones Unidas se deriva de su legalidad, pero se acrecienta en caso de unanimidad. ${ }^{78} \mathrm{Si}$ a estas condiciones particulares se añade un efecto psicológico contingente, como en el caso del 11 de septiembre, la oposición al voto se convierte en una opción irrealizable. Las Resoluciones 1368 del Consejo y 56/1 de la Asamblea se adoptaron por unanimidad, la cual expresó la solidaridad interestatal frente a una amenaza internacional común. ${ }^{79}$ Votadas al día siguiente de los sucesos, el impacto -en la ciudad misma de la sede de la organización- ${ }^{80}$ permanece intacto. De hecho, la sesión del Consejo toma una forma particular: los representantes permanentes no votan a mano alzada sino que deciden permanecer de pie y guardar un minuto de silencio. ${ }^{81}$ Los efectos de los atentados se manifiestan hasta la intervención en Afganistán aprobada por el Consejo en nombre de la legítima defensa. Influyeron la ausencia de líderes del Sur (excepto China) y la participación de una mayoría cercana a Estados Unidos (Bangladesh, Jamaica, Mali, Túnez, Colombia, Mauricio, Singapur). El sentimiento de amenaza común o de causa común también favorece la unanimidad: mientras que el 1994.

${ }^{77}$ Gary Goertz, Contexts of International Politics, Cambridge, University Press,

${ }^{78}$ Claude Inis, "Collective Legitimization as a Political Function of the United Nations”, International Organization, vol. 20, núm. 3, 1966, p. 379.

79 A/56/PV.1: Sudáfrica, Guyana; S/PV.4370 : Bangladesh, China, Colombia, Jamaica, Mauricio, Singapur, Túnez.

${ }^{80} \mathrm{~A} / 56 /$ PV.1 et S/PV.4370.

${ }^{81}$ Anthony Amicelle, “1368 (2001): Menace à la paix et à la sécurité internationales résultant d'actes terroristes”, en Mélanie Albaret et al., op. cit., p. 284. 
Consejo de Seguridad queda bloqueado con respecto a la resolución del conflicto sirio, se votan varios textos desde 2014 frente a la urgencia humanitaria generada por la aparición del Estado Islámico, definido como una amenaza terrorista. ${ }^{82}$

Con respecto al caso iraquí, la muestra de unilateralismo provoca reacciones defensivas de la mayoría de los países del Sur. El contexto se convierte en una barrera. El comportamiento dudoso de los representantes estadounidenses y de sus aliados -espionaje, falsificación de datos ${ }^{83}$ - no hace más que consolidar las posturas del Sur. Por último, la composición del Consejo toma un tinte menos favorable a inicios de 2003. Varios participantes del Sur comparten un fuerte compromiso con el respeto al derecho internacional y un estrecho lazo entre ellos (Chile, México). Siria y Paquistán, por su parte, se ven limitados por preocupaciones internas (consecuencias de la intervención en la frontera siria y una opinión pública hostil en Paquistán).

Los proyectos de intervención en Libia y Siria son indisociables para entender la evolución de las posiciones del Sur. Se presenta aquí un significado cambiante. La convicción de que la OTAN interpretó de forma abusiva la Resolución 1973 conduce a una vasta mayoría a rechazar que se replique el esquema libio. La evolución de la operación en Libia representaría incluso la principal motivación china con respecto a Siria, ${ }^{84}$ más allá de cualquier otro factor, lo que explica los tres vetos impuestos a los proyectos de resolución que implicarían sanciones más severas frente a Siria. Los cambios de postura entre los casos libio y sirio, incluso los votos sobre este último, revelan los temores de países como Sudáfrica. ${ }^{85}$ La hipóte-

82 En orden cronológico: S/RES/2139 (2014), S/RES/2165 (2014), S/ RES/2170 (2014), S/RES/2191 (2014) y S/RES/2199 (2015).

${ }^{83}$ Las armas de destrucción masiva presentadas en la onU jamás se encontrarán como ejemplo.

${ }^{84}$ I-Wei Jennifer Chang, op. cit.

${ }^{85}$ Argumento presentado explícitamente en las justificaciones siguientes: S/ PV.6627 (2011), S/PV.6710 (2012), S/PV.6702 (2012), S/PV.6810 (2012), A/67/ PV.80 (2013). Cuba (A/66/PV.124 (2011), Bolivia y Venezuela (A/66/PV.97 (2011) también se opusieron a toda sanción contra Siria con referencia explícita al precedente libio. 
sis de un posible cambio de régimen también explica la nueva posición de la India ( $c f$. tablas).

En adelante, los votos de gran parte de los países del Sur oscilan en función de los textos ( $c f$. tablas). La tendencia a retomar una posición más defensiva del principio de no intervención se contradice con la necesidad de tomar en cuenta la protección de los derechos humanos en la política exterior.

\subsection{Una respuesta necesaria ante el surgimiento de exigencias relativas a la protección de los derechos humanos}

Como construcciones históricas, la soberanía y su marco jurídico no son inmutables. ${ }^{86}$ Paralelamente, el respeto de los derechos humanos se impuso como una obligación erga omnes, luego de un obiter dictum de la Corte Internacional de Justicia. Los terribles fracasos de la ONU en Ruanda y en los Balcanes en los años noventa introducen una cuestión relativa a las soluciones para evitar violaciones similares, principalmente en caso de bloqueo en el Consejo de Seguridad. Parecía difícil vislumbrar una respuesta que conjuntara eficacia y respeto a la soberanía. ${ }^{87}$ Este proceso de transformación fisura el escudo protector que representaba el derecho internacional al ampliar el campo de aplicación del capítulo viI. Los países del Sur podrían entonces tener interés en bloquear la evolución. Según el enfoque constructivista de las relaciones internacionales, hay transformaciones estructurales que actúan sobre las representaciones de los actores (necesidad de tomar en cuenta los derechos humanos al mantener la seguridad internacional) que como respuesta incitan

${ }^{86}$ Stephen Krasner, Soberanía, hipocresía organizada, Barcelona, Paidós, 2001; y Janice E. Thompson, Mercenaries, Pirates and Sovereigns, Princeton, University Press, 1994.

${ }^{87}$ A partir de 1987, varios debates sobre la injerencia humanitaria atestiguan ya las divergencias importantes sobre la conjugación de la soberanía y la protección de los derechos humanos. Juan Manuel V. Gómez-Robledo, "Universalidad de los derechos humanos y asistencia humanitaria: la evolución inexorable del principio de no intervención”, en Blanca Torres Ramírez y Gustavo Vega (comps.), Relaciones internacionales, México, El Colegio de México, 2010, pp. 133-175. 
tanto a sus socios como al sistema a adaptarse. ${ }^{88}$ De hecho, no se observa un rechazo categórico de los países del Sur de la intervención en nombre de los derechos humanos.

En 2001, los trabajos destinados a responder esta cuestión han forjado el concepto de "responsabilidad de proteger" (R2P). ${ }^{89}$ Cuando un Estado no protege a su pueblo por voluntad o incapacidad, su responsabilidad se transfiere a la "comunidad internacional”, que la ejercerá, si es posible, respetando el capítulo vir. Los debates revelan las disparidades regionales en el Sur: mientras que los países asiáticos se muestran más reticentes -sin oponerse rotundamente-, los latinoamericanos generalmente son prudentes y los participantes africanos ven en la responsabilidad de proteger un medio para obtener más intervención, pues estiman que los países más grandes han desatendido muchas crisis humanitarias regionales. ${ }^{90}$ Cuatro años más tarde, la Asamblea General adopta por consenso el principio de la responsabilidad de proteger, con contornos equívocos, bajo el título de "Deber de proteger a los pueblos contra el genocidio, los crímenes de guerra, la limpieza étnica y los crímenes contra la humanidad". ${ }^{91}$ El documento no es vinculante. Las resoluciones 1970 y 1973 esbozan además un lazo entre responsabilidad de proteger y recurso a la intervención. ${ }^{92}$

88 Dario Battistella, "L'intérêt national. Une notion, trois discours", en Frédéric Charillon (comp.), Politique étrangère, nouveaux regards, París, Presses de Sciences Po, 2002, p. 154 ; y Nicholas Onuf, “Constructivism. A User's Manual”, en Vendulka Kubálková, Nicholas Onuf y Paul Kowert (comps.), International Relations in a Constructed World, Armonk, Sharpe, 1998, p. 59.

${ }^{89}$ Comisión Internacional de la Intervención y la Soberanía de los Estados, La responsabilidad de proteger, Centro de Investigación para el Desarrollo Internacional, Ottawa, 2001 (Informe); Mario Ojeda, “'La responsabilidad de proteger', informe de la Comisión Internacional sobre Intervención y Soberanía del Estado”, Foro Internacional, vol. 43, núm. 1, 2003, pp. 284-288.

${ }^{90}$ Mónica Serrano y Thomas G. Weiss, The International Politics of Human Rights. Rallying to the R2P cause, Nueva York, Routledge, 2014 y Thiago Mattos, Pedro Henrique Souza y Mônica Herz, "Responsabilidade de proteger e ao proteger, e o posicionamento dos BrICs", BRIcs Policy Center, 2012, Policy Brief; Mohammed Ayoob, , op. cit., pp. 105-109.

${ }^{91} \mathrm{~A} / \mathrm{RES} / 60 / 1$ (2005): $\$ 138-139$.

92 Bertrand Badie, “1973 (2011): Jamahiriya Arabe Libyenne”, en Mélanie Albaret et al., op. cit., pp. 556-559. 
Varias organizaciones y Estados del Sur promovieron una intervención en Libia, afirmando que el régimen de Muamar Gadafi había evadido la responsabilidad de proteger a su población. ${ }^{93} \mathrm{El}$ artículo 4h del Acta Constitutiva de la Unión Africana, a veces calificada de cláusula de no indiferencia, hace eco de la R2P. ${ }^{94}$ Debido a que la Liga Árabe y la Unión Africana inspiraron las resoluciones 1970 y 1973, los miembros no permanentes del Consejo no impiden su adopción. ${ }^{95}$ Las reticencias expresadas evitaron criticar a esas organizaciones y se enfocaron en otros temores (interpretación y voluntad de derrocar al régimen en el poder). Brasil propone mejorar la R2P bajo los términos de una protección responsable (Responsabilidad al Proteger, RaP),${ }^{96}$ e insiste en los efectos negativos que pueden acompañar a toda intervención militar, incluidas las legales, y por tanto recuerda que esta alternativa sigue siendo una solución de último recurso. ${ }^{97}$

Parece prematuro sacar conclusiones definitivas sobre la posición de los del Sur con respecto a este nuevo concepto, como atestiguan

${ }^{93}$ En la votación de la Resolución 1970: Brasil, Colombia, Líbano, Nigeria (S/ PV.649).

94 "Artículo 4. Principios: La Unión Africana funciona conforme a los principios siguientes: [...] (h) El derecho de la Unión a intervenir en un Estado miembro bajo decisión de la Conferencia, en ciertas circunstancias graves, a saber: los crímenes de guerra, el genocidio y los crímenes contra la humanidad”. En 2003 se adoptó un protocolo de enmienda al Acta Constitutiva de la Unión, pero aún no entra en vigor. Olivier Corten, "L'Union africaine, une organisation régionale susceptible de s'émanciper de l'autorité du Conseil de sécurité ? Opinio juris et pratique récente des Etats", Conference Paper, European Society of International Law, noviembre de 2012.

${ }^{95}$ Sobre Libia, S/PV.6491 (2011): Brasil, China, la India, Líbano; y S/PV.6498 (2011): China; Sobre Siria, A/66/PV.97 (2011): la India; S/PV.6711 (2012): Sudáfrica, la India.

${ }^{96}$ Carta enviada a la Asamblea General y al Consejo de Seguridad por la representante de Brasil, A/66/551-S/2011/701, 11 de noviembre de 2011.

97 Thorsten Benner, "Brazil as a Norm Entrepreneur: the 'Responsibility While Protecting' Initiative”, Global Public Policy Institute (GPPi), 2013 (Working Paper); y Andreas S. Kolb, "The Responsibility to Protect (R2P) and the Responsibility While Protecting (RwP): Friends or Foes?”, Global Governance Institute (GGI), 2012 (Analysis Paper 6). 
las reacciones de los participantes más reticentes, ${ }^{98}$ pero también, de forma más general, sobre las dudas del Sur en el caso sirio. La propaganda en favor de la intervención militar de ciertos representantes de la Liga Árabe -Arabia Saudita y Qatar en mente- ya no basta para solidarizar a los socios en desarrollo. Se observa también una división entre, por un lado, los adversarios de las sanciones y de la intervención, que critican la parcialidad de los textos y el involucramiento de ciertas partes (del Sur) en el terreno (véanse las tablas 1 y 2); y por el otro, aquéllos que les reprochan a los primeros paralizar la onu en detrimento de la protección de los derechos humanos. ${ }^{99}$ De manera general, las resoluciones relacionadas con la situación de los derechos humanos en Siria obtienen más votos positivos que las que promueve específicamente algún grupo de Estados, más explícitamente politizadas (véase la tabla 2).

\section{Conclusión}

El enfoque poliheurístico de la política exterior nos ha permitido constatar la diversidad de las posturas del Sur y su fluctuación en función de los proyectos de intervención militar en el marco de la ONU. Su posición depende de la interacción de múltiples variables, cuyo peso oscila según las circunstancias. En este sentido, la interpretación de una amenaza a la paz y la seguridad internacionales que amerite recurrir a la fuerza realza los dilemas políticos para los países del Sur. Más que una sacralización del principio de no intervención, estos actores buscan, clásicamente, conservar una situación favorable o modificar las que no lo son tanto. ${ }^{100}$ Este argumento no significa, en absoluto, que no exista ninguna dife-

98 Denuncia del concepto por los países del ALBA, e Irán, principalmente en los debates sobre Libia. A/66/PV.89 (2011), pp. 19-20.

${ }^{99}$ Costa Rica denuncia que China (y Rusia) usen el veto en el Consejo (A/66/ PV.97). Arabia Saudita, encargada de presentar la Resolución 67/262, se manifiesta abiertamente contra el régimen sirio; el texto se aprueba con una gran abstención (A/67/PV.80).

${ }^{100}$ James Rosenau, The Scientific Study of Foreign Policy, Nueva York, Free, 1971. 
rencia entre los Estados del Sur y los desarrollados. Los objetivos que se persiguen al elegir apoyar $u$ oponerse a un proyecto de intervención militar colectiva divergen.

En vista de la repartición del poder entre Estados a escala global, los representantes del Sur tienen interés en promover la no intervención. El derecho internacional constituye un atenuante de los efectos de las asimetrías. En este sentido, la operación libia influyó mucho en la prudencia de los representantes del Sur con respecto a Siria. Además, la historia recuerda los riesgos de tales desviaciones para varios países en desarrollo, se trate de intervenciones sufridas o realizadas. El unilateralismo de la administración republicana de George W. Bush cuando la guerra en Iraq de 2003 es un símbolo de los temores del Sur.

No obstante, observar las posiciones de los Estados en desarrollo lleva a reconocer que éstos votan regularmente en favor de los proyectos de intervención militar colectiva. A partir de esta constatación, la tesis soberanista sólo conserva validez en ciertas circunstancias; no puede entenderse como una cuestión de principios de los países del Sur.

En efecto, otras variables intervienen en la toma de decisiones y llevan a relativizar la defensa de la no injerencia. El apoyo a intervenciones militares colectivas puede, por ejemplo, mejorar la imagen ante la gran potencia y, en consecuencia, recolectar beneficios de escala internacional, pero también interna. El recurso a la fuerza también provoca una redistribución de los mapas regionales, y son muchos los que pretenden sacar beneficios de ello. Así, las crisis libia y siria despertaron más las ambiciones de Arabia Saudita y de Qatar de lo que contribuyeron a provocar un reflejo de protección de la soberanía.

Sin embargo, perseguir objetivos egoístas no siempre desemboca en el apoyo de proyectos de intervención militar colectiva, y puede, al contrario, fortalecer la necesidad de conservar el escudo protector jurídico vigente. La calidad de las relaciones bilaterales con Estados Unidos influye en las posturas del Sur. Así, los más acérrimos defensores de la soberanía y críticos vigorosos de las evoluciones del derecho con respecto a la responsabilidad de proteger son también gobernantes fríos frente a Washington: los países de 
ALbA, Irán, Corea del Norte, Myanmar o Zimbabue. Para nuestros cuatro casos de estudio, el temor ante la desestabilización local y la orientación antiestadounidense de las mayorías en Medio Oriente y Asia Central contribuyeron a limitar el apoyo a las intervenciones. Tal fue el caso de países del Golfo y de Paquistán con la guerra de Iraq de 2003. El límite que impone la opinión pública es aún permisivo; los representantes la pueden esquivar en función del peso de otras variables.

Por último, el contexto juega un papel en la toma de decisiones y prohíbe cualquier automatismo. El impacto de los atentados del 11 de septiembre mató toda crítica a pesar de las dudas sobre las consecuencias locales de la operación afgana, como murmuraron Mali y Túnez. Al contrario, el precedente libio constituyó un cerco para el proyecto de intervención en Siria. La degradación de la situación humanitaria y la amenaza del Estado Islámico permitieron regresar al consenso, aún demasiado frágil para facilitar la resolución del conflicto.

A pesar de ese precedente, los votos en el Consejo de Seguridad y en la Asamblea General demuestran las dudas del mundo en desarrollo. Los países del Sur no ignoran la cuestión de los derechos humanos, pero constituye solamente una variable en construcción. La operación libia confirma su prudencia.

La asimetría de las relaciones de fuerza sesga el debate sobre la no intervención. A falta de poder material, les resta el peso del número. Los actores del Sur tradicionalmente se han agrupado para poner en juego la restricción colectiva (G-77, Movimiento de los No Alineados, los "G" de la omc, etc.). El unilateralismo de unos favorece el acercamiento de los otros. Mientras que los países en desarrollo no presentan posturas comunes frente a nuestros casos de estudio, las acciones de Estados Unidos ante Iraq y de la oTAN en Siria obligan a cerrar más las filas. De hecho, si los atentados del 11 de septiembre retardaron la creación del Foro la India-Brasil-Sudáfrica (IBAS), éste se lanzó en junio de 2003, tres meses después de la operación Libertad Iraquí. De forma similar, Brasil y Sudáfrica se abstienen con respecto a Siria en 2011 para alinearse con el grupo de los BRICs. Oponerse a las iniciativas -cuestionables a sus ojos- de los que tergiversaron el 
proyecto libio $^{101}$ es ahora más importante que las críticas internas y externas sobre el abandono de la causa de los derechos humanos. En consecuencia, la evolución del debate y del derecho dependerá más de la política de seducción y del restablecimiento de la confianza rota que de la imposición tanto por parte de los países del Norte como entre los socios del Sur.

Traducción de Ana Inés Fernández Ayala

${ }^{101}$ Narnia Bolher-Muller, "Nuanced Balancing Act: South Africa's National and International Interests and its 'African Agenda'”, sAIIA, 2012 (Occasional Paper núm. 120), p. 6; y "Dilma irrita Itamaraty com abstenção na ONU”, O Estado de São Paulo, 4 de octubre de 2011. 


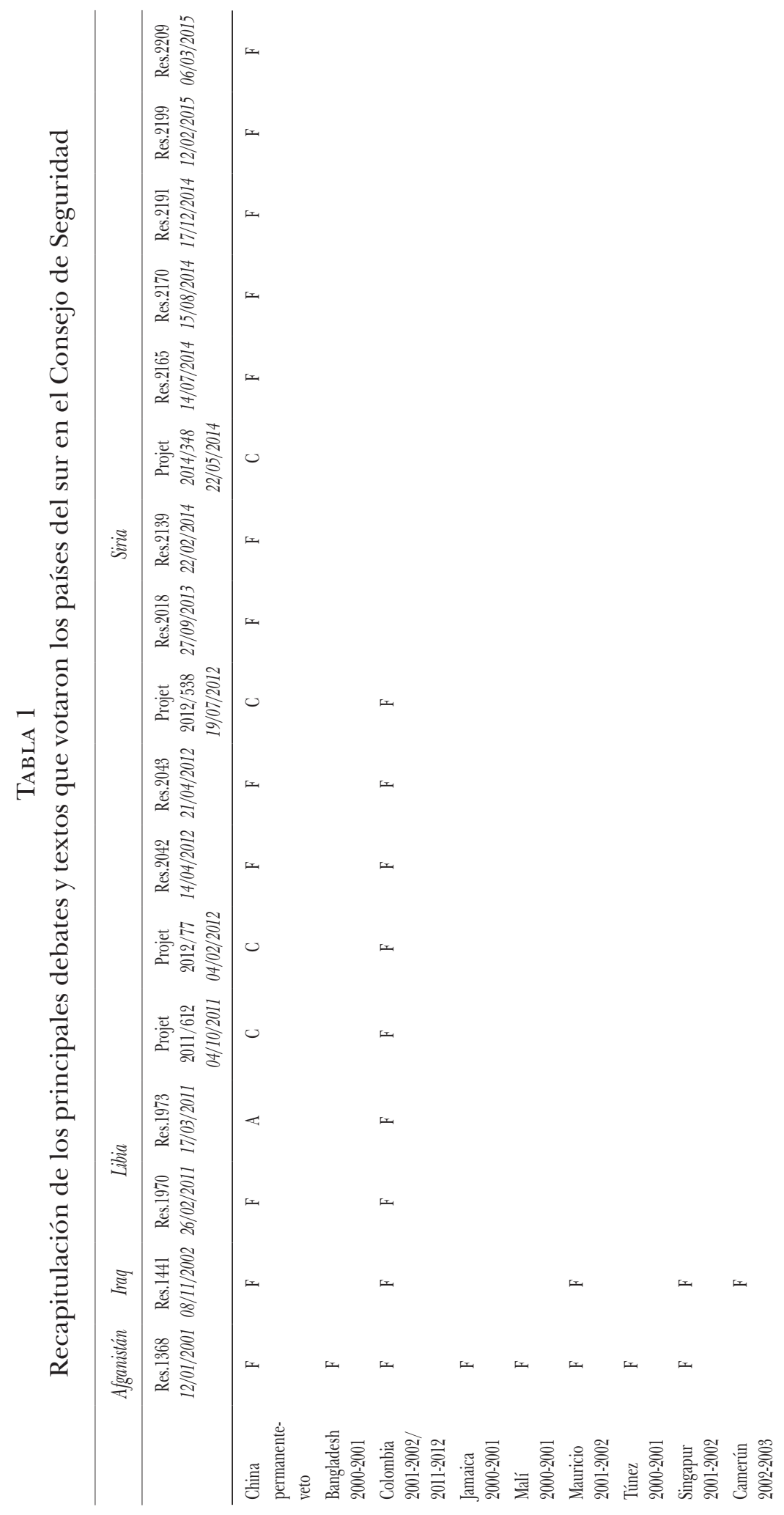




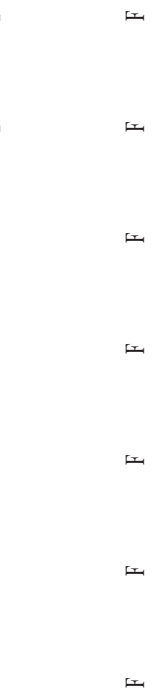

$-$

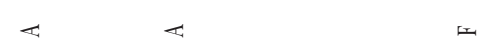

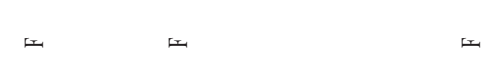

I I I I t

厌石圷

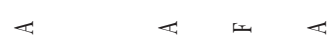

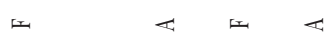

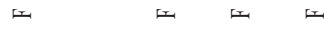

도 도 도

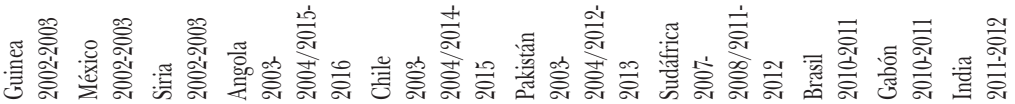




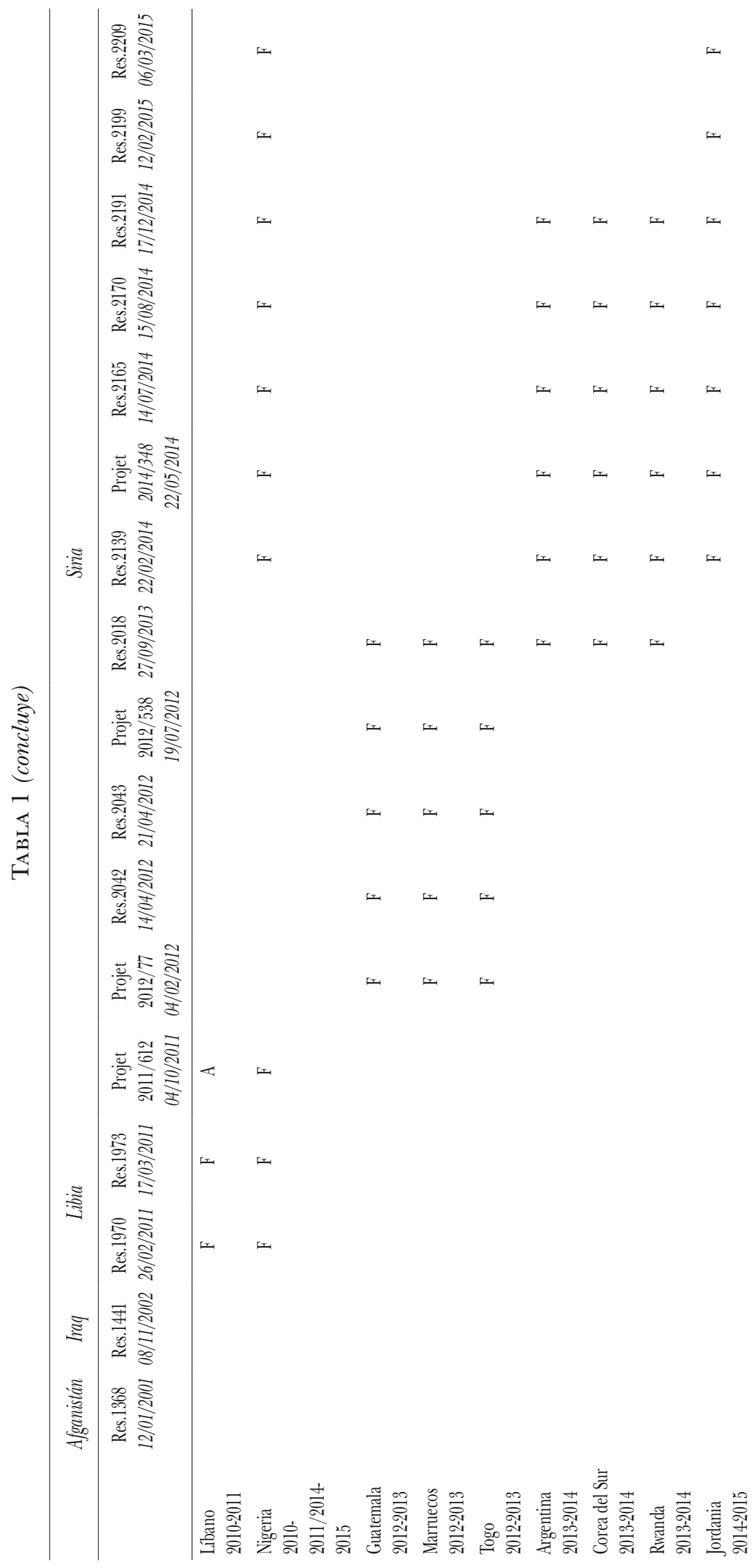




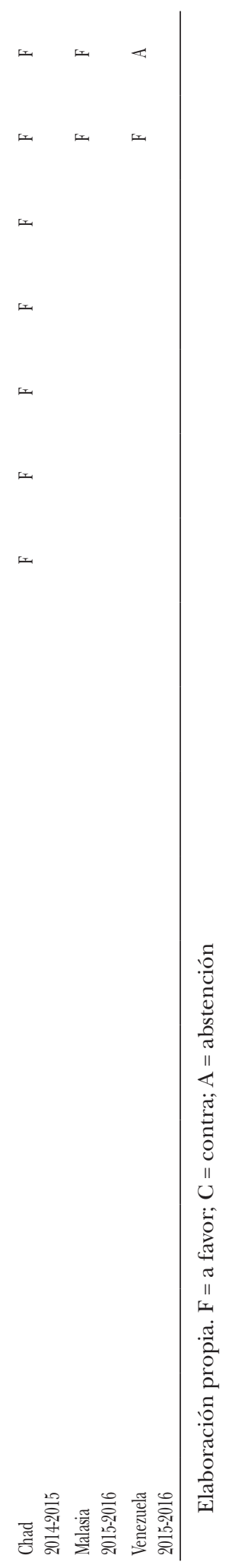




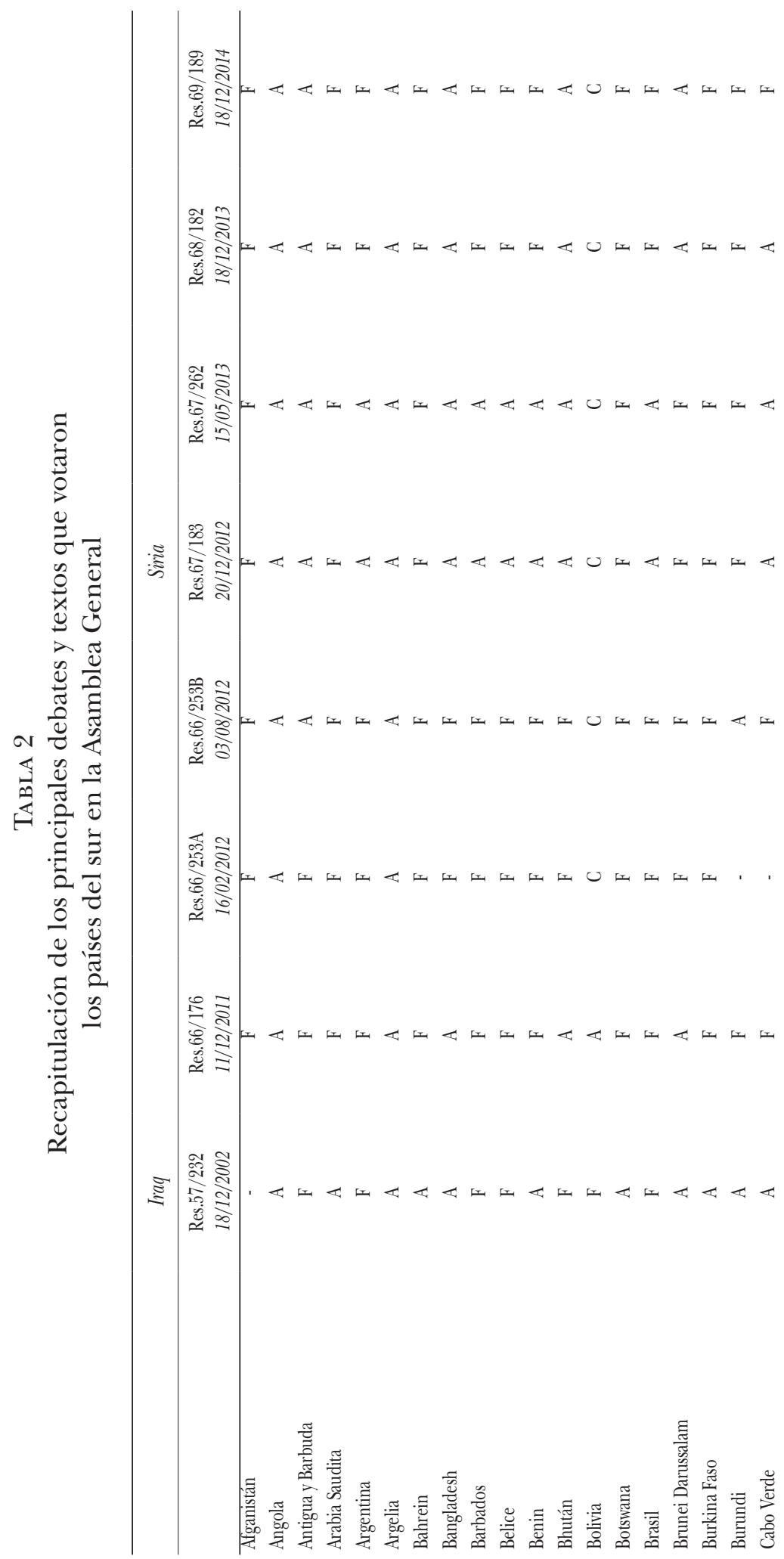




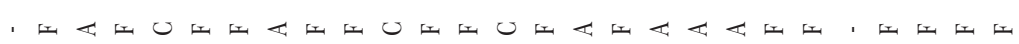

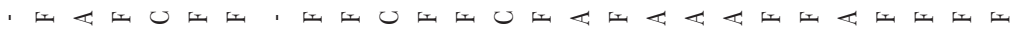

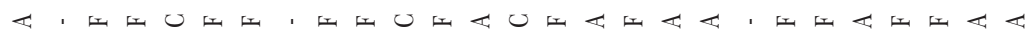

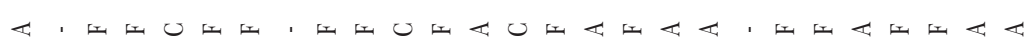

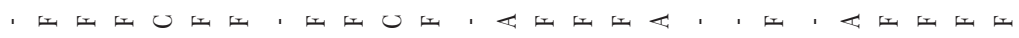

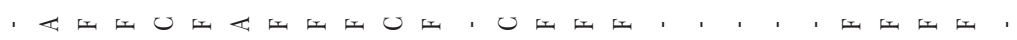

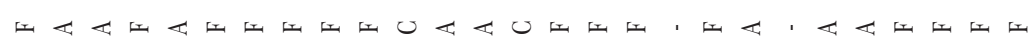

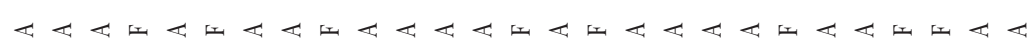

蓉芯 


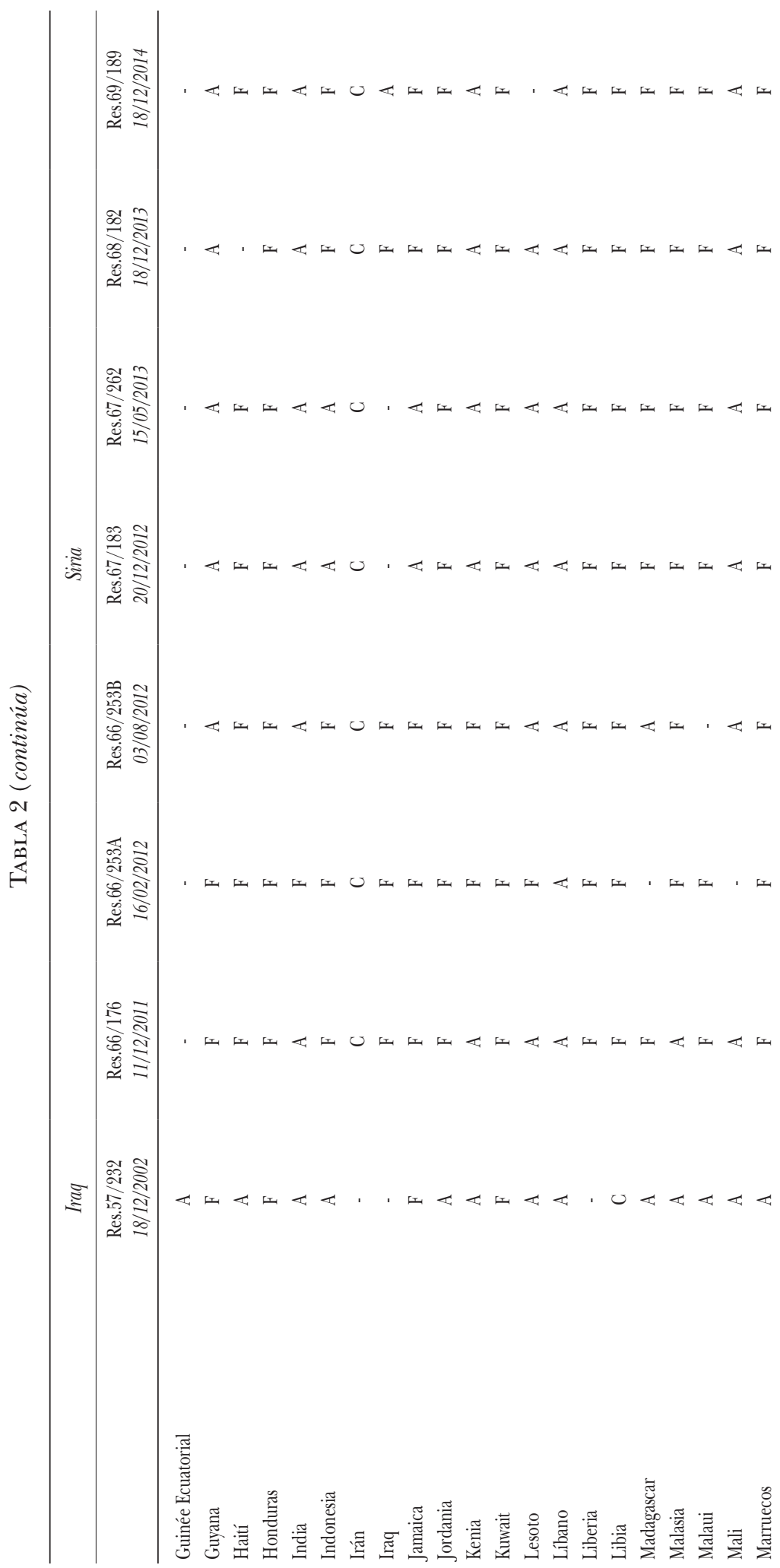




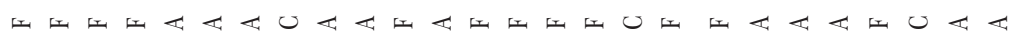

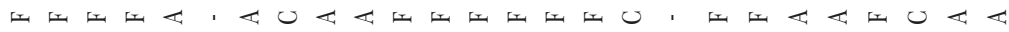

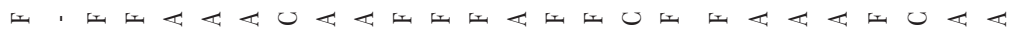

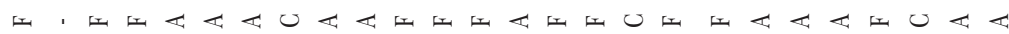

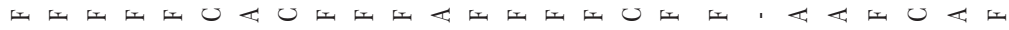

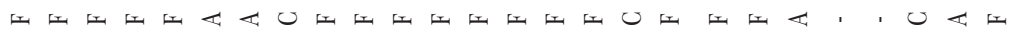

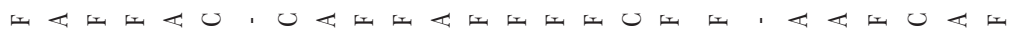

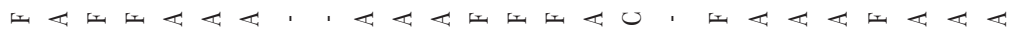

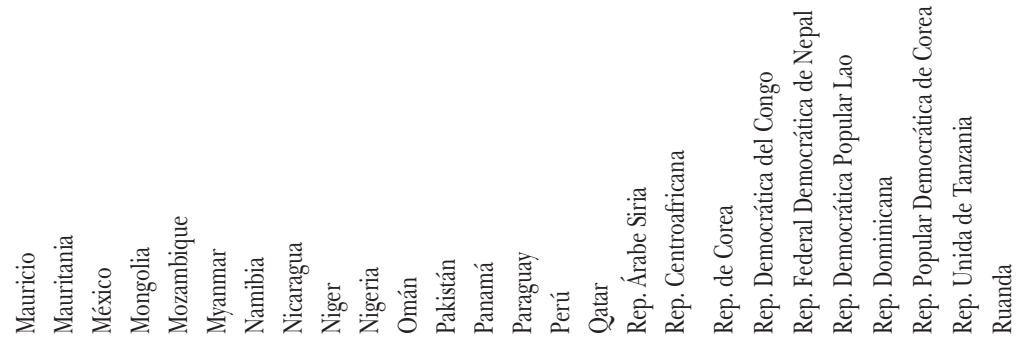




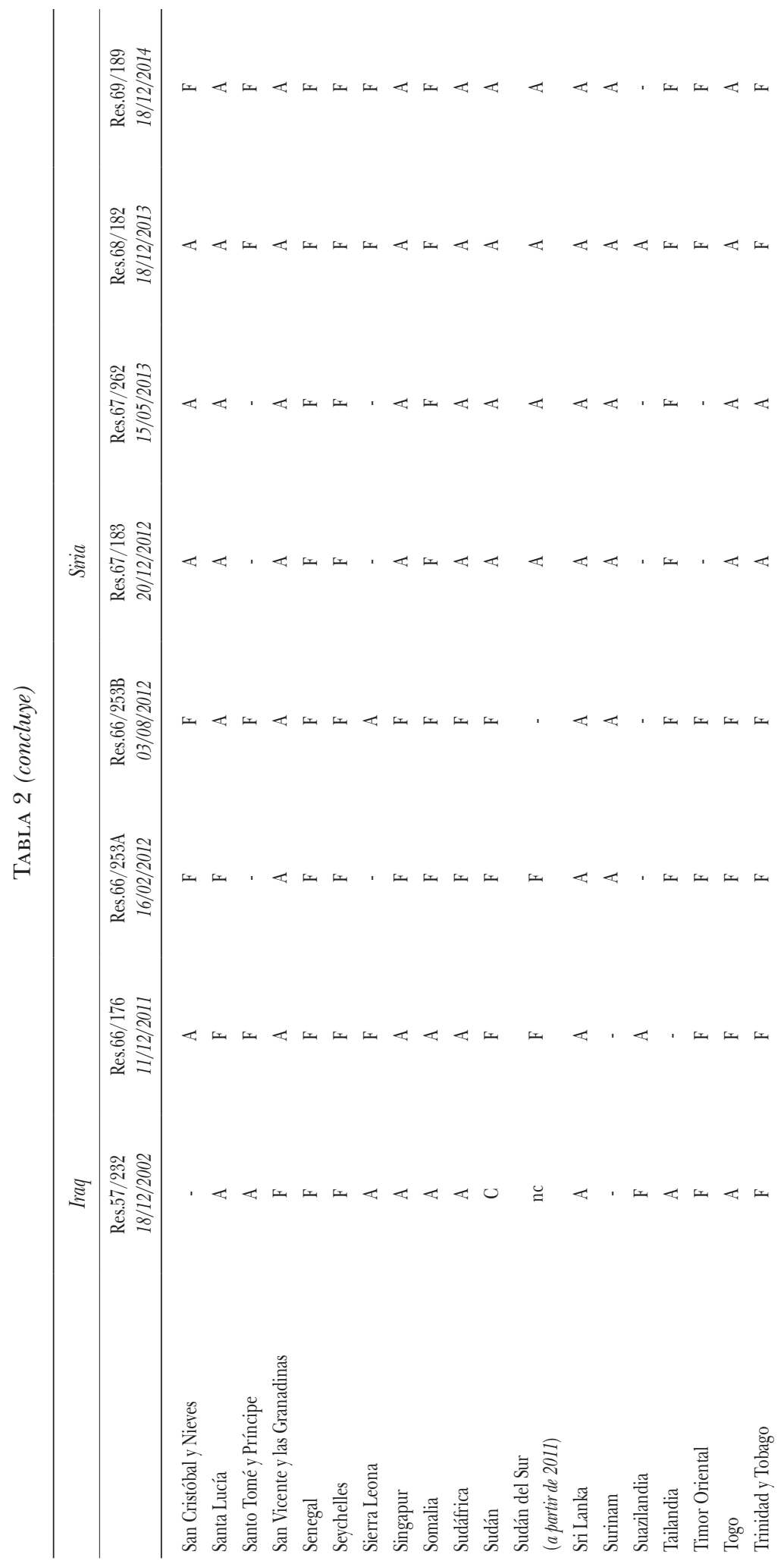




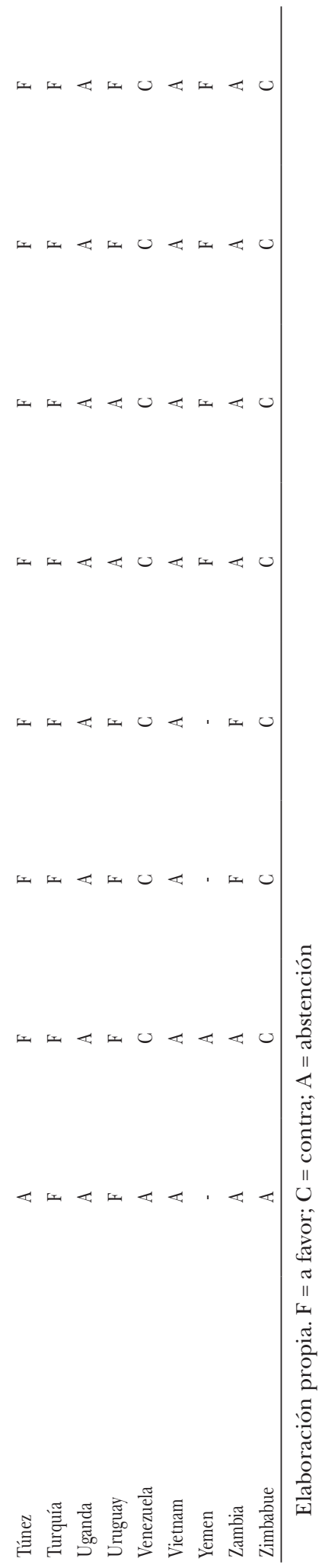




\section{BibLIOGRAFÍA}

Adebajo, Adekeye, Adebayo Adedji y Chris Landsberg, South Africa in Africa: the Post-Apartheid Era, Scottsville, University of KwaZulu-Natal, 2007. Amicelle, Anthony, "1368 (2001): Menace à la paix et à la sécurité internationales résultant d'actes terroristes", en Mélanie Albaret et al. (comps.), Les grandes résolutions du Conseil de sécurité des Nations Unies, París, Dalloz, 2012, pp. 283-291.

Amin, Shahid, "Post 9/11 Developments in Pakistan's Foreign Policy”, en Pakistan's Foreign Policy: a Reappraisal, $2^{\mathrm{a}}$ ed., Karachi, Oxford University Press, 2010, pp. 315-341.

Amorim, Celso, "Primeiros passos: Iraque", en Breves narrativas diplomáticas, São Paulo, Benvirá, 2013, pp. 15-33.

Ayoob, Mohammed, "Third World Perspectives on Humanitarian Intervention and International Administration”, Global Governance, vol. 10, núm. 1, 2004, pp. 99-118.

Barah, Mikail, "Le paradoxe diplomatique du Qatar comme moyen d'accès à la consécration", Revue Internationale et Stratégique, núm. 69, 2008, pp. 31-41.

Badie, Bertrand, "1973 (2011): Jamahiriya Arabe Libyenne”, en Mélanie Albaret et al. (comps.), Les grandes résolutions du Conseil de sécurité des Nations Unies, París, Dalloz, 2012, pp. 550-563.

Badie, Bertrand, Le temps des humiliés, París, Odile Jacob, 2014.

Battistella, Dario, "La politique étrangère", en Théories des relations internationales, París, Presses de Sciences Po, 2012, pp. 373-411.

Battistella, Dario, "L'intérêt national. Une notion, trois discours", en Frédéric Charillon (comp.), Politique étrangère, nouveaux regards, París, Presses de Sciences Po, 2002, pp. 139-166.

Benner, Thorsten, "Brazil as a Norm Entrepreneur: the 'Responsibility While Protecting' Initiative”, Global Public Policy Institute (GPPi), 2013 (Working Paper).

Bolher-Muller, Narnia, "Nuanced Balancing Act: South Africa's National and International Interests and its 'African Agenda", South African Institute of International Affairs (SAIIA), 2012 (Occasional Paper núm. 120).

Borda Guzmán, Sandra, "La internacionalización del conflicto armado después del 11 de septiembre: ¿la ejecución de una estrategia diplo- 
mática hábil o la simple ocurrencia de lo inevitable?”, Colombia Internacional, núm. 65, 2007, pp. 66-89.

Carlson, Allen, "Helping to Keep the Peace (Albeit Relunctantly): China's Recent Stance on Sovereignty and Multilateral Intervention”, Pacific Affairs, vol. 77, núm. 1, 2004, pp. 9-27.

Chang, I-Wei Jennifer, "Chinese Policies on the Arab Spring", en Robert Mason (comp.), Popular Unrest and Foreign Policy: The International Politics of the Arab Spring, Basingstoke, Palgrave Macmillan, 2014, por publicar.

Claude, Inis, "Collective Legitimization as a Political Function of the United Nations”, International Organization, vol. 20, núm. 3, 1966, pp. 367-379.

Commission Internationale de l'Intervention et de la Souveraineté des Etats, La responsabilité de protéger, Centre de recherches pour le développement international, Ottawa, 2001 (Informe).

Corten, Olivier, "L'Union africaine, une organisation régionale susceptible de s'émanciper de l'autorité du Conseil de sécurité ? Opinio juris et pratique récente des Etats", Conference Paper, European Society of International Law, 2012.

Corten, Olivier y François Dubuisson, "La guerre "anti-terroriste" engagée par les États-Unis a-t-elle été autorisée par le Conseil de sécurité?”, Journal des Tribunaux, año 120, núm. 6034, 2001, pp. 889-895.

Covarrubias, Ana, "Los derechos humanos en la política exterior de México: ¿en defensa propia o de los valores liberales?”, en Ana Covarrubias (comp.), Temas de política exterior, México, El Colegio de México, 2008, pp. 303-332.

Droz-Vincent, Philippe, "Les dilemmes des régimes arabes après l'intervention américaine en Irak”, Politique Étrangère, vol. 68, núm. 3-4, 2003, pp. 553-566.

Fair, Christine C., The Counterterror Coalitions: Cooperation with Pakistan and India, Santa Monica, RAND Project Air Force, 2004.

Fermandois, Joaquín, "Chile y la Guerra de Irak", Bicentenario, vol. 7, núm. 1, 2008, pp. 45-78.

Flemes, Daniel, "Regional Power South Africa: Co-operative Hegemony Constrained by Historical Legacy”, Journal of Contemporary African Studies, vol. 27, núm. 2, 2009, pp. 135-157.

Foot, Rosemary, "Chinese Strategies in a US-Hegemonic Global Order: Accomodating and Hedging”, International Affairs, vol. 82, núm. 1, 2006, pp. 77-94. 
Galindo, Alejandra, "Los desafíos de los países del Consejo de Cooperación del Golfo ante la crisis de Siria: Arabia Saudita y Qatar", en Gilberto Conde (comp.), Levantamiento popular y guerra civil en Siria: repercusiones internacionales, México, El Colegio de México, por publicar.

Goertz, Gary, Contexts of International Politics, Cambridge, University Press, 1994.

Gómez-Robledo, Juan Manuel V., "Universalidad de los derechos humanos y asistencia humanitaria: la evolución inexorable del principio de no intervención", en Blanca Torres Ramírez y Gustavo Vega (comps.), Relaciones internacionales, México, El Colegio de México, 2010, pp. 133-175.

Gutekunst, Volker, "Developing Countries and the Legitimacy of Military Intervention 1990-2009", tesis de maestría, Relaciones Internacionales, IEP, París-Freie Universität de Berlín, 2009.

Herz, Mônica y Lucas Pérez Florentino, "Os Brics e as revoltas no Oriente Médio e Norte da África”, Brics Policy Center, 2011 (Policy Brief).

Jaffrelot, Christophe, "Chapitre introductif. Les quatre points cardinaux de la diplomatie indienne: le régional et le global, l'idéalisme et le réalisme", en Christophe Jaffrelot (comp.), New Delhi et le monde, París, Les Presses de Sciences Po, 2008, pp. 7-31.

Keohane, Robert O., "Lilliputians' Dilemmas: Small States in International Politics", International Organization, vol. 23, núm. 2, 1969, pp. 291-310.

Khatib, Lina, "Qatar's Foreign Policy: the Limits of Pragmatism", International Affairs, vol. 89, núm. 2, 2013, pp. 417-431.

Kolb, Andreas S., "The Responsibility to Protect (R2P) and the Responsibility While Protecting (RwP): Friends or Foes?”, Global Governance Institute (GGI), 2012 (Analysis Paper 6).

Krasner, Stephen, Soberanía, hipocresía organizada, Barcelona, Paidós, 2001.

La Balme, Nathalie, "Opinion publique et politique étrangère: l'évolution du débat”, en Frédéric Charillon (comp.), Politique étrangère, nouveaux regards, París, Presses de Sciences Po, 2002, pp. 193- 211.

Lage, Victor Countinho, "Os BRICS nas resoluções sob o capítulo VII da Carta da Organização das Nações Unidas após a Guerra Fria”, BRICS Policy Center, 2011 (Policy Brief).

Lagrange, Philippe, "1674 (2006): Protection des civils dans les conflits armés”, en Mélanie Albaret et al. (comps.), Les grandes résolutions du Conseil de sécurité des Nations Unies, París, Dalloz, 2012, pp. 446-459. 
Laidi, Zaki, "BRICs: Sovereignty Power and Weakness”, International Politics, vol. 49, núm. 5, 2012, pp. 614-632.

Lecoutre, Delphine, "La gestion de la crise libyenne par l'Union africaine. Chronique d'une impuissance annoncée", Laboratoire de l'Irsem, 2012 (Ministère français de la défense, núm. 11).

Lima, Maria Regina Soares y Mónica Hirst, "Brazil as an Intermediate State and Regional Power: Action, Choice and Responsibilities", International Affairs, vol. 82, núm. 1, 2006, pp. 21-40.

Mattos, Thiago, Pedro Henrique Souza, y Mônica Herz, "Responsabilidade de proteger e ao proteger, e o posicionamento dos BRICS", BRICS Policy Center, 2012 (Policy Brief).

Milewski, Pawel, "Pakistan and India and the Events of September 11", Polish Quarterly of International Affairs, vol. 11, núm. 1, 2002, pp. 123-141.

Mintz, Alex (comp.) "The Poliheuristic Theory of Foreign Policy Decision Making”, Journal of Conflict Resolution, vol. 48, núm. 1, 2004, pp. 3-126.

Muñoz, Heraldo, A Solitary War, Golden, Col., Fulcrum, 2008.

Nathan, Laurie, "Consistencies and Inconsistencies in South African Foreign Policy”, International Affairs, vol. 81, núm. 2, 2005, pp. 361-372.

Novosseloff, Alexandra, "The Role of Emerging Countries in the United Nations", en Christophe Jaffrelot (comp.), Emerging States: The Wellspring of a New World Order, París, Presses de Sciences Po, 2008, pp. 231-243.

Ojeda, Mario, “'La responsabilidad de proteger', informe de la Comisión Internacional sobre Intervención y Soberanía del Estado”, Foro Internacional, vol. 3, núm. 1, 2003, pp. 284-288.

Onuf, Nicholas, “Constructivism. A User's Manual”, en Vendulka Kubálková, Nicholas Onuf y Paul Kowert (comps.), International Relations in a Constructed World, Armonk, Sharpe, 1998, pp. 58-78.

Pellicer, Olga, "Los dilemas de México en el Consejo de seguridad", en Rafael Fernández de Castro (comp.), En la frontera del imperio, México, Planeta, 2003, pp. 91-104.

Perrot, Sandrine, "Les nouveaux interventionnismes militaires africains. Une redéfinition des conditions de la puissance au Sud du Sahara?", Politique Africaine, núm. 98, 2005, p. 111-130.

Placidi-Frot, Delphine, “1441 (2002): La situation entre l'Iraq et le Koweït”, en Mélanie Albaret et al. (comps.), Les grandes résolutions du Conseil de sécurité des Nations Unies, París, Dalloz, 2012, pp. 313-329. 
Racine, Jean-Luc, "Quête de puissance, multipolarité et multilatéralisme", en Christophe Jaffrelot (comp.), New Delhi et le monde, París, Les Presses de Sciences Po, 2011, pp. 32-53.

Rigoulet-Roze, David, "Le Qatar: un paradoxe géopolitique et une anomalie géoéconomique”, Géoéconomie, núm. 62, 2012, pp. 53-66.

Rosenau, James, The Scientific Study of Foreign Policy, Nueva York, Free, 1971. Rowinsli, Jan, "Position of China Regarding September 11", Polish Quarterly of International Affairs, vol. 11, núm. 1, 2002, pp. 32-56.

Russett, Bruce, Controlling the Sword. The Democratic Governance of National Security, Cambridge, Harvard University Press, 1990.

Serrano, Mónica y Thomas G. Weiss, The International Politics of Human Rights. Rallying to the R2P cause?, Nueva York, Routledge, 2014.

Soulé-Kohndou, Folashadé, Puissances émergentes et multilatéralisme: le cas de l'Afrique du Sud (1999-2008). Analyse des srtatégies d'une puissance émergente, París, L'Harmattan, 2010.

Stuenkel, Oliver, "The BRICs and the Future of R2P", Global Reponsability to Protect, vol. 6, núm. 1, 2014, pp. 3-28.

Tawil Kuri, Marta, "Siria: Estabilidad interna y poder regional en un entorno conflictivo", en Luis Mesa Delmonte (comp.), Las relaciones exteriores de Siria, México, El Colegio de México, 2013, pp. 31-78.

Thakur, Ramesh, The United Nations, Peace and Security. From Collective Security to the Responsibility to Protect, Cambridge, University Press, 2006.

Thompson, Janice E., Mercenaries, Pirates and Sovereigns, Princeton, University Press, 1994.

Wallensteen, Peter y Patrik Johansson, "Security Council Decisions in Perspective", en David M. Malone (comp.), The UN Security Council: From the Cold War to the 21st Century, Boulder, Lynne Rienner Publishers, 2004, pp. 181-193. 